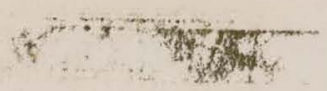

\title{
FAST-MIXED SPECTRUM REACTOR PROGRESS REPORT
}

\section{RESULTS OF THE FMSR BENCHMARK CALCULATIONS AND AN ASSESSMENT OF CURRENT FISSION PRODUCT LIBRARIES}

\author{
With contributions from members of \\ the ANL Applied Physics Division, \\ the MIT Nuclear Engineering Department, and \\ the ORNL Engineering Physics Division \\ June 1980 \\ Prepared for the \\ DIVISION OF REACTOR RESEARCH AND TECHNOLOGY \\ UNITED STATES DEPARTMENT OF ENERGY \\ BROOKHAVEN NATIONAL LABORATORY \\ ASSOCIATED UNIVERSITIES, INC. \\ UNDER CONTRACT NO. DE-ACO2-76CH00016 \\ UNITED STATES DEPARTMENT OF ENERGY
}




\section{DISCLAIMER}

This report was prepared as an account of work sponsored by an agency of the United States Government. Neither the United States Government nor any agency Thereof, nor any of their employees, makes any warranty, express or implied, or assumes any legal liability or responsibility for the accuracy, completeness, or usefulness of any information, apparatus, product, or process disclosed, or represents that its use would not infringe privately owned rights. Reference herein to any specific commercial product, process, or service by trade name, trademark, manufacturer, or otherwise does not necessarily constitute or imply its endorsement, recommendation, or favoring by the United States Government or any agency thereof. The views and opinions of authors expressed herein do not necessarily state or reflect those of the United States Government or any agency thereof. 


\section{DISCLAIMER}

Portions of this document may be illegible in electronic image products. Images are produced from the best available original document. 
BNL 51237

UC-77

(Gas Cooled Reactor Technology - TID-4500)

\section{FAST-MIXED SPECTRUM REACTOR PROGRESS REPORT}

\section{RESULTS OF THE FMSR BENCHMARK CALCULATIONS AND AN ASSESSMENT OF CURRENT FISSION PRODUCT LIBRARIES}

H. Ludewig, C. Durston, B. Atefi, and R.J. Cerbone

With contributions from members of the ANL Applied Physics Division, the MIT Nuclear Engineering Department, and

the ORNL Engineering Physics Division

June 1980

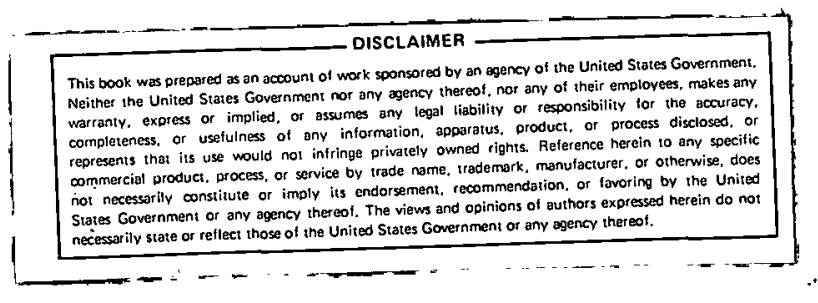

\footnotetext{
H.J.C. KOUTS, CHAIRMAN

W.Y. KATO, DEPUTY CHAIRMAN

DEPARTMENT OF NUCLEAR ENERGY, BROOKHAVEN NATIONAL LABORATORY

UPTON, NEW YORK 11973
} 


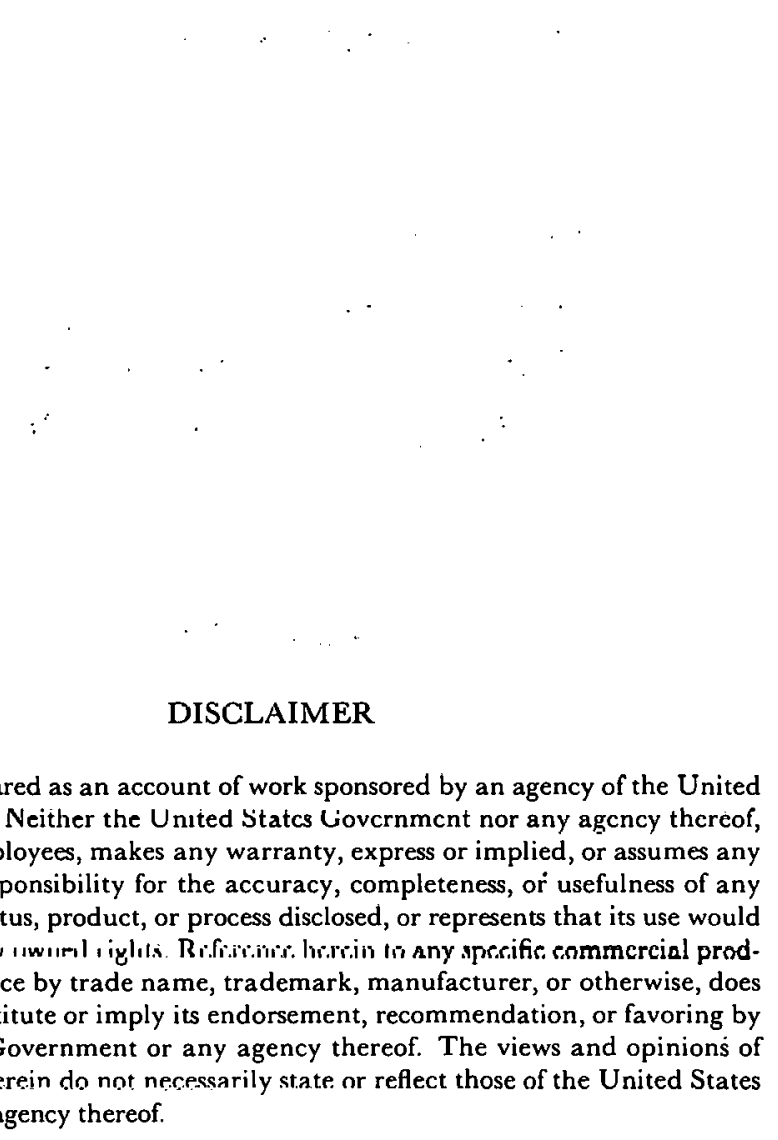

This book was prepared as an account of work sponsored by an agency of the United Siales Guveriment. Neither the United Statcs Lovcrnment nor any agcncy thercof, nor any of their employees, makes any warranty, express or implied, or assumes any legal liability or responsibility for the accuracy, completeness, or usefulness of any information, apparatus, product, or process disclosed, or represents that its use would

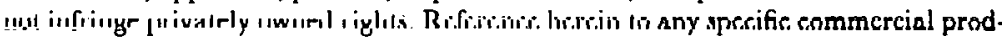
uct, process, or service by trade name, trademark, manufacturer, or otherwise, does not necessarily constitute or imply its endorsement, recommendation, or favoring by the United States Government or any agency thereof. The views and opinions of authors expressed herein do not necessarily state or reflect those of the United States Government or any agency thereof.

Printed in the United States of America

Available from

National Technical Information Service

U.S. Department of Commerce

.5285 Port Royal Road

Springfield, VA 22161

Price: Printed Copy $\$ 5.25 ;$ Microfiche $\$ 3.00$ 


\section{ABSTRACT}

As part of the Initial Feasibility Study of the Fast Mixed Spectrum Reactor, a series of benchmark calculations were made to determine the sensitivity of the physics analysis to differences in methods and data. Argonne National Laboratory ( $A N^{-}$), the Massachusetts Institute of Technology (MIT), and Oak Ridge National Laboratory (ORNL) were invited to. participate with Brookhaven National Laboratory in the analysis of a FMSR model prescribed by BNL. Detailed comparisons are made including a comprehensive study on the adequacy of the fission product treatments. 
THIS PAGE

\section{WAS INTENTIONALLY LEFT BLANK}


TABLE OF CONTENTS

Page

ABSTRACT. . . . . . . . . . . . . . . . . .

LIST OF TABLES. . . . . . . . . . . . . . . . . . . v vii

LIST OF FIGURES ..................... . . ix

1. INTRODUCTION. . . . . . . . . . . . . . . . . 1

2. INTERCOMPARISON OF BENCHMARK CALCULATIONS..$\cdots \cdots$

2.1 INTRODUCTION . . . . . . . . . . . . . 3

2.2 DESCRIPTION OF THE BENCHMARK PROBLEM . . . . . . . . 4

2.2.1 Group Collapsing Considerations ......... 6

2.2.2 Fission Product Models............. 8

2.2.3 Comparison of $k$ and Breeding Ratio ....... 10

2.3 COMPARISON OF ONE-GROUP INTEGRAL PARAMETERS...$\cdots 12$

2.3.1 Comparisons in the Fast Regions . . . . . . . 13

2.3.2 Comparisons in the Transition Fast to Epithermal

Spectrum Region............. 16

2.3.3 Comparisons in the Epithermal Spectrum Region . . 18

2.3.4 Spectral Shift Effects............. 20

2.3.b Effect of Group Collapse on One-Group Cross Sections 21

3. FISSION PRODUCTS. . . . . . . . . . . . . 26

3.1 INTRODUCTION . . . . . . . . . . . . . 26

3.2 FISSION PRODUCT MODEL USED IN THE INITIAL FMSR

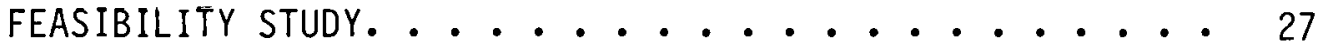

3.3 CURRENTLY USED FISSION PRODUCT MODEL . . . . . . . . 27

3.4 EFFECT OF SCATTERING MATRIX. . . . . . . . . 28 


\section{TABLE OF CONTENTS (Cont.)}

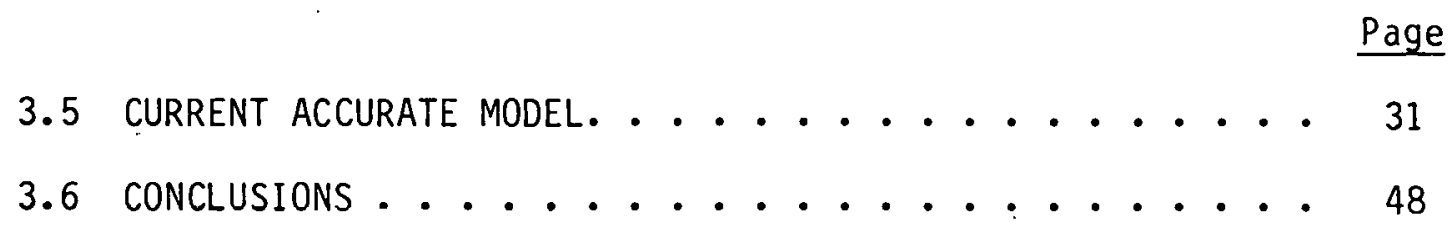

4. CONCLUSIONS. . . . . . . . . . . . . . 50

REFERENCES . . . . . . . . . . . . . . . 52 


\section{LIST OF TABLES}

$\underline{\text { Table }}$

$\underline{\text { Page }}$

2.1 Methods and Data Utilized by FMSR Benchmark Calculations. . 7

2.2 Benchmark Results .............. 11

2.3 One-Group Fission Cross Sections (Zone 19 Reactor Center (Low Burnup); Zone 32 Fast Region (High Burnup)). . ... . 14

2.4 One-Group Absorption Cross Sections (Zone 19 Reactor Center (Low Burnup); Zone 32 Fast Region (High Burnup)). . . . 15

2.5 One-Group Fission Cross Sections (Zone 34 Transition. Fast to Epithermal Spectrum Region).......... 17

2.6 One-Group Absorption Cross Sections (Zone 34 Transition Fast to Epithermal Spectrum Region) . . . . . . 17

2.7 One-Group Fission Cross Sections (Zone 10 Epithermal Spec-

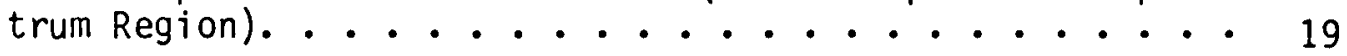

2.8 One-Group Absorption Cross Sections (Zone 10 Epithermal Spectrum Region)....................... 19

2.9 Comparison of Spectral Indices. . . . . . . . 22

2.10 Group Structure for BNL 10-Group Library. . . . . . 23

2.11 Comparison of BNL 10-Group and 50-Group Calculations

One-Group Cross Sections. .............. 24

3.1 Garrison-Roos Scheme. . . . . . . . . 29

3.2 Comparison Between the Lumped Macroscopic Absorption Cross Section of the Exact and the Two-Lump "Odd-Even" Model (Cross Sections Due to Pu-239 Fission in the Soft Spectrum

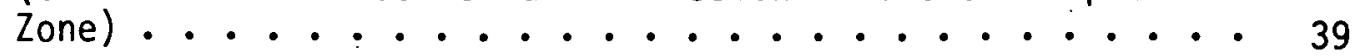

3.3 Comparison Between the Lumped Macroscopic Absorption Cross Section of the Exact and the One-Lump Model Generated at. $68,000 \mathrm{MWD} / \mathrm{MT}$ (Cross Sections Due to Pu-239 Fission in the Soft Spectrum Zone) ............ 


\section{LIST OF TABLES (cont.)}

Table

Page

3.4 Comparison Between the Lumped Macroscopic Absorption Cross Section of the Exact and the Garrison-Roos Model (Cross Sections Due to Pu-239 Fission in the Soft Spectrum Zone). . . . . . . . . . . . . 42

3.5 Comparison Between the Lumped Macroscopic Absorption Cross Section of the Exact and the Two-Lump Model (Cross Sections Due to Pu-233 Fission in the Hard Spectrum 7 nne). . . . 45

3.5 Cunparisun Between the Lumped Macroscopir Ahsnrptinn Cross Section of the Exact and the Olle-Lump Model Gencrated at $68,000 \mathrm{MWD} / \mathrm{MT}$ (Cross Sections Due to Pu-239 Fission in the Hard Spectrum Zone) ................ . . 46

3.7 Comparison Between the Lumped Macroscopic Absorption Cross Section of the Exact and the Garrison-Roos Model (Cross Sections Due to Pu-239 Fission in the Hard Spectrum Zone) 


\section{LIST OF FIGURES}

Figure

Page

2.1 R-Z Model for Benchmark Study . . . . . . . . . . 5

2.2 Sigma Absorption Total Lumped Fission Products. . . . . . 9

3.1 FMSR Fission Product Absorption History . . . . . . 30

3.2 Representative FMSR Hard and Soft Spectra . . . . . . 33

3.3 Sequence of Calculations Used in Fission Product Studies. - 34

3.4 Lumped Fission Product Absorption Cross Section of Odd-A, Even-A and All Isotopes Due to the Fission of Pu-239 in the Soft Spectrum . . . . . . . . . . . . . 36

3.5 Even- and Odd-A Isotopes Buildup in the Soft Spectrum Zone as a Function of Burnup............... . 36

3.6 Even and Odd Fraction of Fission Products Due to Fission of Pu-239 in the Soft Spectrum as a Function of Burnup. • 37

3.7 One-Lumped Macroscopic Cross Section Based on the Exact and Garrison-Roos Treatment as a Function of Burnup . . . 44

3.8 Lumped Microscopic Cross Section of Fission Products Due to Pu-239 Fission in the Hard Spectrum. . . . . . . . 44 


\section{THIS PAGE}

\section{WAS INTENTIONALLY LEFT BLANK}

$-x-$ 


\section{INTRODUCTION}

As part of the Initial Feasibility Study of the Fast Mixed Spectrum Reactor (FMSR) carried out during FY 1979, a series of benchmark calculations were undertaken to deternine the sensitivity of the physics analysis to differences in methods and data. Argonne National Laboratory (ANL), the Massachusetts Institute of Technology (MIT), and Oak Ridge National Laboratory (ORNL) were invited to participate with Brookhaven National Laboratory (BNL) in the analysis of a FMSR model prescribed by BNL.

Each participant utilized current state of the art methods available at their respective installations. The model selected was the reference design discussed extensively in the Initial Feasibility Report. (1)

The primary conclusions of the benchmark activities are:

1. For the reference design, overall agreement between the participatiny calculations was reasonable for parameters such as eigenvalue and breeding ratio. For the equilibrium $B O E C$ and EOEC, the results agreed to within $1.5 \%$ in $\mathrm{k}_{\mathrm{e}}$, with ANL showing the largest deviation from the average.

2. Of all the effects studied, the treatment of fission product cross sections is clearly the most important contributor to the observed differences. This led BNL to implement a inore sophisticated treatment than available in the initial calculations. Many of the differences between the ANL and BNL results were then resolved.

3. Since spatial spectral effects are very important in the FMSR, care must be exercised in generating region-wise few-group cross sections. In particular, the local breeding ratio is quite sensitive to the 
calculation of the local spectrum and treatment of the resolved resonance region. Differences in determining local breeding, especially in the moderator region, can significantly impact the performance of the FMSR.

4. The results of the benchmark calculations indicate that all the methods and data predict essentially the same results, provided the analyses take int.n account the need to carefully treat the spatial dependence of the neirernn spectipull.

5. Analyses of the benchinark results led to a careful review of the available fission product treatments. A new "two lump" treatment has been developed which predicts results in good agreement with those obtained with an exact treatment.

This report will summarize the results of benchmark calculations in Section 2. A detailed discussion on fission product treatments will be given in Section 3 and the conclusions of the study are summarized in Section 4. 


\section{INTERCOMPARISON OF BENCHMARK CALCULATIONS}

\subsection{INTRODUCTION}

The fact that differences can exist between different establishments ostensibly calculating the same system has been highlighted in papers by Weisbin et al.(2) at Atlanta in 1974 and a Los Alamos report in 1978 by Kidman et a).(3) in 1974. These differences stem from the various approximations utilized to obtain solutions to that system. These approximations may be inherent in the basic system at an establishment or introduced by the analyst who fails to select the most appropriate model, either by lack of awareness or confinement to available methods. These circumstances can be financial (i.e., the computer code used runs for too long a time), spatial (i.e., the computer menory is too small or the algorithms are not sufficiently design-oriented to handle a detailed problem), and logistical (the manpower and resources are not available to do a more detailed survey within the time allotted).

The FMSR benchmark analyzed was performed by four participants: ANL, BNL, MIT and ORNL. The calculation was based on an early FMSR design by BNL which incorporated engineering design considerations such as power flattening and coolability. The original calculations by BNL were as detailed as possible within the constraints imposed by the version of the $2 \mathrm{DE}(4)$ code available on the Brookhaven CDC-7600 computer. The 2DB code is essentially group independent, as far as space on the computer is concerned, thus permitting the use of the LIB-IV 50-group cross-section library. (5) The use of 50 groups was a conpromise between excessive running time and adequate detail in the energy description of the cross sections which was needed to properly represent the larye number of different design options which needed to be considered in the early 
stages of the project. The fast regions of the FMSR are relatively innocuous as far as calculational methods are concerned. However, the introduction of the moderator seems to introduce significant spectral effects necessitating the use of a large number of groups to properly represent the low energy region and the spatial spectral shifts associated with burnup. The large number of groups also tends to mitigate some of the problems associated with few-group cross sections such as those generated with the $10 x(6)$ system, notably in the elastic removal area and in the resolved resunance region.

In the following section, the benchmark problem is described, integral parameters are compared, the effect of group collapsing is discussed, as well as the fission product models used, and relevant one-group cross sections are compared.

\subsection{DESCRIPTION OF THE BENCHMARK PROBLEM}

In order to compare methods and data in use at the different laboratories, an early design of the FMSR, which contains all the essential features of this reactor type designated the "reference" design, was selected for the benchmark. An $R-Z$ model was specified in as much detail as was possible within the restrictions of the $2 D B$ version in use on the BNL CDC-7600 computer. A schematic representation of this $R-Z$ mivdel is shown in Figure 2.1. The radial direction was represented by 108 meshpoints; 18 meshpoints were used in the axial direction. The upper and central fuel regions were modeled by 34 reyiuris corresponding to the 34 cycles of the "equilibrium" fuel management scheme. However, the axial blanket was modeled in less detail because of computer space limitations. In the FMSR, there is no radial blanket in the sense of an LMFBR because fuel assemblies that start off in "radial blanket" positions eventually become core 


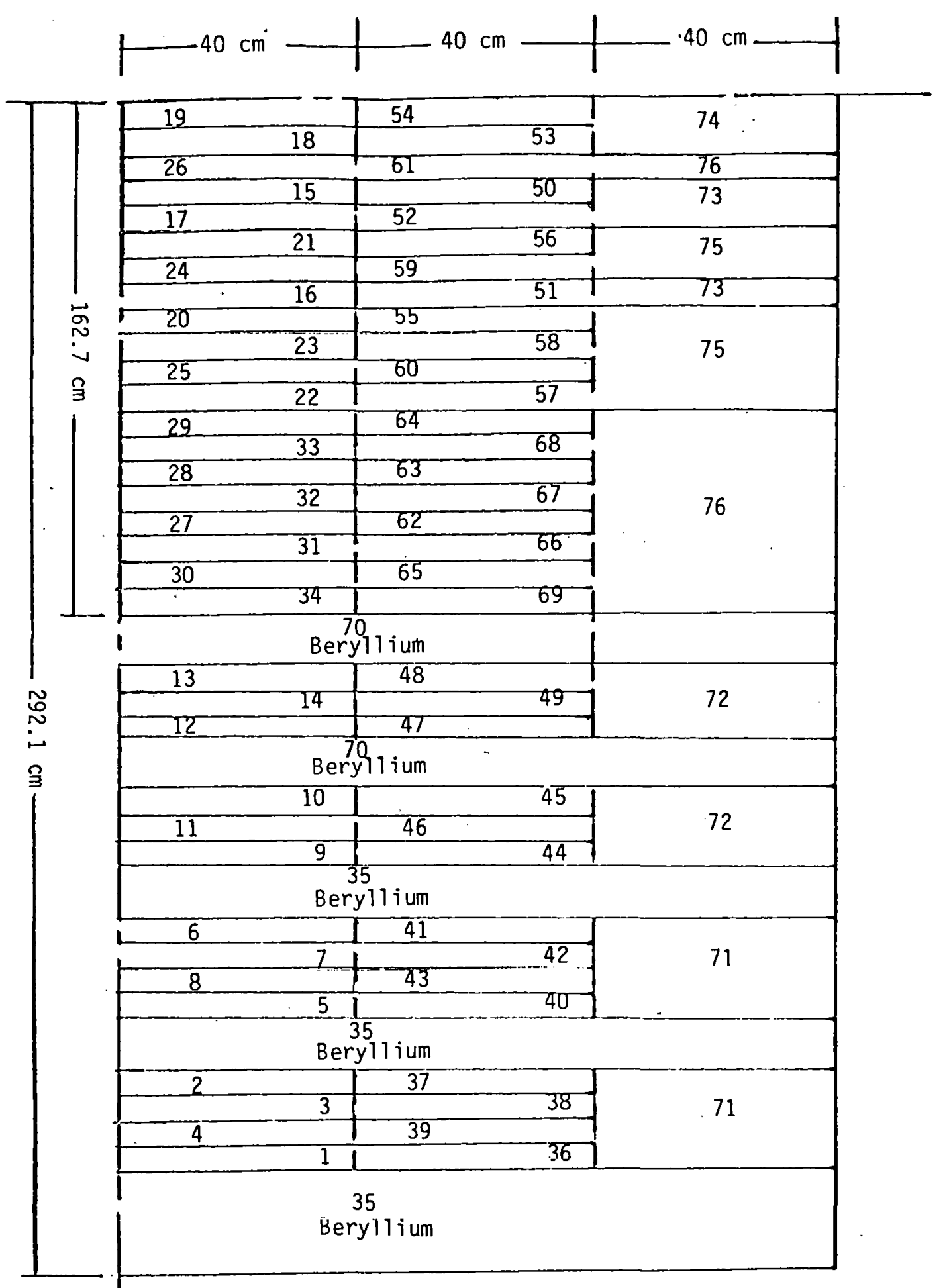

Figure 2.1. R-Z Model for Benchmark Study 
assemblies in later cycles. One of the adjustable parameters in an FMSR design is the cycle length between fuel inanagement shuffles. In the BNL calculations, a cycle time of 185 days was selected based on the best available data at that time. The cycle time has subsequently been increased to compensate for data deficiencies partly uncovered by this comparison.

The benchmark was calculated at BNL using the 50-group LIB-IV neutron cross-section set processed by the 1DX code with no group collapsing. MIT elected to use the same basic LIB-IV cross-section set processed by the SPHINX code, but due to cost considerations, both in running time and computer storage, used 10 energy groups. ORNL was al so constrained by cost, al though not in size, to use 9 groups processed through their AMPX system. Although ANL had the capability to perform 50-group calculations using the DIF3D code with cross sections processed by the MC ${ }^{2}-S D X$ system, the basic ARC system modules coupled to REBUS dictated the use of eight energy groups. The DIF3D code also had limited editing capabilities since it is a relatively recent addition to ANL's library. Table 2.1 summarizes the computational methods employed by edch participant in the benchmark calculations.

\subsubsection{Group Collapsing Considerations}

Group collapsing is used to save computer runring time and storage, and is the normal mode of operation in the fast reactor community both in the USA and abroad. However, in the case of the FSMR, indiscriminate group collapsing can yield some surprising results in all designs with the exception, perhaps, of an all-fast system. BNL selected 50 energy groups because it was recognized that in the initial design phase, with a wide variety of reactor configurations under consideration, no specific collapsed cross-section set would adequately accommodate all designs. Further custom group collapsing for each new design 
Table 2.1

Methods and Data Utilized by FMSR Benchmark Participants

\begin{tabular}{|c|c|c|c|c|c|c|}
\hline Calculation & BNL-1 & BNL-2 & MIT-1 & MIT-2 & ANL & ORNL \\
\hline Basic Cross Sections & ENDF/B-IV & ENDF/B-IV & ENDF/B-IV & ENDF/B-IV & ENDF/B-IV & ENDF/B-IV \\
\hline $\begin{array}{l}\text { Intermediate } \\
\text { Processing Code }\end{array}$ & MINX & MINX & MINX & MINX & $M C^{2}-2$ & AMPX \\
\hline $\begin{array}{l}\text { Intermediate Library } \\
\text { Groups }\end{array}$ & $50 / L I B-I V$ & $50 / L$ IB-IV & $50 / L I B-I V$ & $50 / L I B-I V$ & 171 & 126 \\
\hline $\begin{array}{l}\text { Fission Product } \\
\text { Cross Sections }\end{array}$ & C.7 NSFP & $\begin{array}{l}\text { ENDF/B } \\
\text { Scheme }\end{array}$ & .2 .7 NSFP & $\begin{array}{l}\text { JAPANESE } \\
1 \text {-Lunip }\end{array}$ & $\begin{array}{l}\text { ENDF/B } \\
\text { Scheme }\end{array}$ & $\begin{array}{l}\text { ORIGEN } \\
\text { Produced }\end{array}$ \\
\hline $\begin{array}{l}\text { Processing code for } \\
\text { Broad Groups }\end{array}$ & $10 X$ & $10 x$ & SPHINX & SPHINX & SDX & XSDRN \\
\hline Number of Broad Groups & 50 & 50 & 10 & 10 & 8 & 9 \\
\hline Fuel MET Code & $F 2 D B$ & $F 2 D B$ & $2 \mathrm{DB}$ & $2 \mathrm{DB}$ & REBUS-DIF3D & CITATION \\
\hline
\end{tabular}


would involve a large amount of preprocessing, data manipulation, and human time consumption with the 1DX code. It was, therefore, simpler and safer to utilize 50 energy groups, albeit at the expense of additional calculational time.

ANL demonstrated that if the collapsing is done properly, then the results, as far as eigenvalues are concerned, differ by less than a half a percent in $\mathrm{ke}$. However, this applies lu unly one point in the fuel residence time. In the rMSK, however, the compusitions change markedly during the life of the fuel assemblies. As will be seen later, the ANL breeding ratio comparisons, especially in the outer zones ( 1 and 2 ), show enough variation to have an effect on the equilibrium cycle since these small effects are additive. This could not be directly confirmed because the ANL fuel cycle calculations were performed with only 8 groups and 17 double cycle lengths instead of the BNL prescribed 34 cycles.

\subsubsection{Fission Product Models}

The fission product cross-section representations used by ENL were based on LIB-IV which, in turn, is based on the Garrison-Roos lumping scheme. (7) In this representation, xenon and samarium are treated explicitly; lumps are used to represent the non-saturating, slowly saturaliny dild iajidly saturating groups. No scattering matrices are included for the lumps. Two llodels were used by BNL. The first, designated BNL-1, used the non-saturating lump only; the cross-section magnitudes were multiplied by 2.7 to account for the other fission products. The second model, designated BNL-2, is based on all five cross-section sets. ANL àlso used a Garrison and Roos scheme to produce a single lumped fission product. MIT used an evaluation from Japan by Kikuchi et al.,(8) seen compared with ENDF/B-V in Figure 2.2, and ORNL used an ORIGEN 


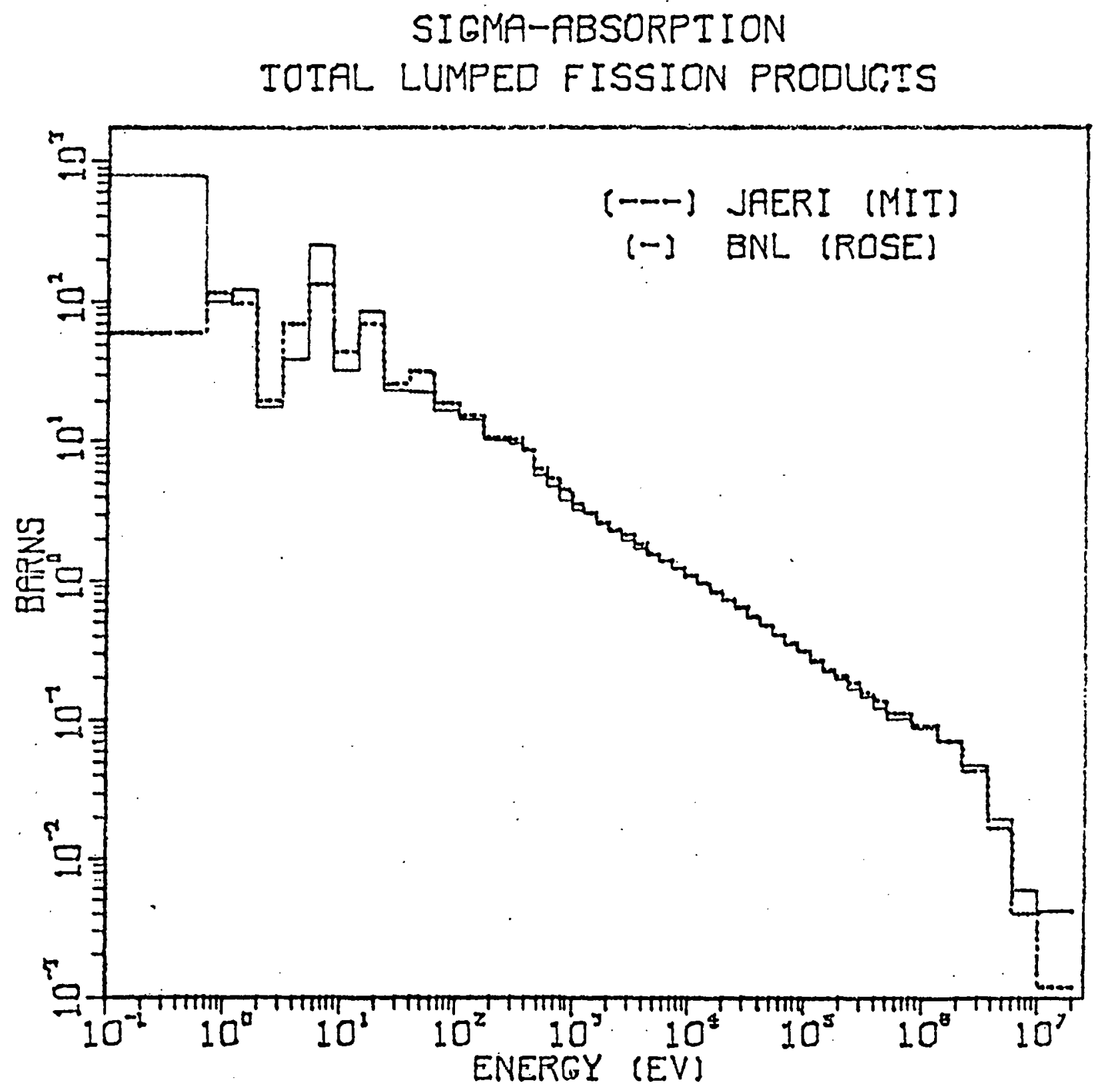

Figure 2.2. 
based, zone-dependent, lumped fission product. The ORNL fission product cross sections tend to be somewhat lower than their GCFR-based set in the regions that control the reactivity of the FMSR, again an indication of the sensitivity of the results to zone-wise cross-section representation upon collapse to few groups. A subsequent study showed that at the 50-group level, the cross sections are much less zone dependent, except in the lower energy groups. This. would suggest the use of one global lump at the 50-group level provided it were generated for the moderator zone; it would theretore yield the rnrrect. result.s for the moderated zone and reasonably good results for the fast zones where there is little sensitivity to epithermal group cross sections. The resulting one-group cross sections are compared in a later section.

As a result of the uncertainties in the lumped fission product cross sections and models, a detailed study of the fission product behavior as a function of burnup was carried out at BNL and is discussed in Section 3.

\subsubsection{Comparison of $\mathrm{ke}$ and Breeding Ratio}

Table 2.2 shows a comparison of the integral parameters calculated by the four benchmark participants. Two sets of results are given for BNL (BNL-1 and BNL-2) which correspond to different fission product treatments. The BNL-1, MIT, ORNL and ANL calculations all utilize essentially the same fission product treatment; namely, a single non-saturating lump. Thus, these four calculations had the same fission product inventory and the same cycle.. length (185 days). The second BNL calculation, BNL-2, was carried out using five fission products (Xe-135, Sm-149, rapidly, slowly and non-saturating lumps) and a cycle length of 220 days.

Both BNL-1 and MIT-1 calculations were made without a scattering matrix for the fission products to provide a more consistent comparison. ORNL 
Table 2.2

Benchmark Results

\begin{tabular}{|c|c|c|c|c|c|}
\hline \multirow[b]{2}{*}{ Participant } & \multirow{2}{*}{$\begin{array}{c}\text { Fission Product } \\
\text { Library }\end{array}$} & \multicolumn{2}{|c|}{ Eigenvalue $K$} & \multicolumn{2}{|c|}{ Breeding Ratio* } \\
\hline & & $\mathrm{BOC}$ & EOC & $\mathrm{BOC}$ & EOC \\
\hline BNL-1 & LIB-IV-Lump & 0.982 & 1.000 & 1.68 & 1.61 \\
\hline$B N L-2$ & $\begin{array}{l}\text { LIB-IV-5 } \\
\text { Fission Products }\end{array}$ & 0.977 & 0.993 & 1.67 & 1.57 \\
\hline MIT-1 & LIB-IV & 0.986 & 1.004 & 1.67 & 1.60 \\
\hline MIT-2 & JAPANESE & 0.969 & 0.987 & 1.68 & 1.61 \\
\hline ORNL & ORNL-4 & 0.979 & 1.002 & 1.66 & 1.58 \\
\hline ANL & ENDF/B-III & 0.966 & 0.983 & 1.66 & $\star \star$ \\
\hline AVERAGE & & $0.977 \pm 0.007$ & $0.995 \pm 0.008$ & 1.67 & \\
\hline
\end{tabular}

${ }^{*} B R=\frac{\text { Captures in }(U-238 \& \text { Pu-240) }}{\text { Absorptions in }(P u-239 \& \mathrm{Pu}-241)}$

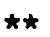

Not available 
estimated that the scattering matrix is worth about $-0.6 \%$ in multiplication factor. Calculations made at BNL indicate a decrease of $1.4 \%$ in $\mathrm{ke}_{\mathrm{e}}$ when the fission product scattering matrix is approximated by the scattering matrix for natural molybdenum.

The fission product model used in the BNL-2 series of calculations indicates that an even longer cycle time than 220 days is required. A $240-$ day cycle time would ensure that the value of $k_{e}$ is unity at the end of the equilibrium cycle.

An inspection of Table 2.2 shows the following:

1. All of the calculations agree with the average to within one percent in $k_{e}$;

2. Agreement in calculated breeding ratio is excellent;

3. Differences between the calculations can be attributed in large part to the fission product treatment;

4. The methods and data for all practical purposes are essentially equivalent. However, as will be shown in the tollowing sections, the treatment of the highly spatially-dependent spectra needs to be handled with care, especially in the resolved resonance region.

\subsection{COMPARISON OF ONE-GROUP INTEGRAL PARAMETERS}

To explore further the salient differences between the calculational models and data used in the benchmark analyses, a series of comparisons between calculated integral parameters is presented. These include one-group cross sections and spectral indices. The comparisons have been collected for the three representative regions of the reactor; namely, fast, transition fast to epithermal, and epithermal zones. The zone designations correspond to the BNL designations as shown in Figure 2.1 and are: 
1. Zone 19 corresponds to the central fast spectrum region composed of low enriched fuel with an accumulated fission product inventory corresponding to one fourth of the reactor total.

2. Zone 32 is all in the fast region and has a high fissile enrichment with a high fission product concentration.

3. Zone 34 is similar to Zone 32 but next to the beryllium moderator, and therefore, more sensitive to the local epithermal spectrum.

4. Zone 10 corresponds to the inner moderated region composed of partially enriched fuel with a low fission product concentration.

\subsubsection{Comparisons in the Fast Regions}

Table 2.3 compares fission cross sections in the two fast regions, Zones 19 and 32. As expected, there is little sensitivity of the fissile cross sections to the different cross-section generating methods. However, for the fertile isotopes, U-238 and Pu-240, there are some differences though not large (6 to $12 \%)$. These differences can be attributed to differences in representing the fission cross sections near the thresholds for fission.

Table 2.4 compares the absorption cross sections in the fast region. For the fissile and fertile isotopes, the trends indicated in Table 2.3 are repeated. Since the absorption is pretty much dominated by fission in the fast regions, this is not surprising.

In the case of the fission products, the differences are of the order of $25 \%$. This is to be expected considering the differences in treatment. However, when the une-lump fission product used in the BNL-I treatment is replaced by the more explicit treatment used in BNL-2, agreement between BNL, ORNL and ANL is quite good (4 to $7 \%$ ). The high one-group absorption cross sections for MIT stem from the higher fission product cross sections inherent in the Japanese evaluation. 
Table 2.3

One-Group Fission Cross Sections

Zone 19 Reactor Center (Low Burnup)

\begin{tabular}{|c|c|c|c|c|c|}
\hline Nuclide & $\begin{array}{c}\text { ANL } \\
\text { 8 Groups }\end{array}$ & $\begin{array}{c}\text { MIT } \\
\text { IU Groups }\end{array}$ & $\begin{array}{c}\text { ORNL } \\
\text { Groups }\end{array}$ & $\begin{array}{c}\text { BNL } \\
\text { Go Gruups }\end{array}$ & 50 GNL Giups \\
\hline U-235 & 1.50 & 1.53 & 1.49 & 1.50 & 1.50 \\
U-238 & .034 & .036 & .033 & .036 & .037 \\
Pu-239 & 1.61 & 1.63 & 1.61 & 1.62 & 1.62 \\
Pu-240 & .354 & .369 & .347 & .368 & .370 \\
Pu-241 & 1.96 & 2.00 & 1.95 & 1.97 & 1.96 \\
\hline
\end{tabular}

Zone 32 Fast Region (High Burnup)

\begin{tabular}{|c|c|c|c|c|c|}
\hline Nuclide & $\begin{array}{c}\text { ANL } \\
8 \text { Groups }\end{array}$ & $\begin{array}{c}\text { MIT } \\
10 \text { Groups }\end{array}$ & $\begin{array}{c}\text { ORNL } \\
\text { Groups }\end{array}$ & $\begin{array}{c}\text { BNL } \\
50 \text { Groups }\end{array}$ & $\begin{array}{c}\text { BNL* } \\
\text { Groups }\end{array}$ \\
\hline U-235 & 1.49 & 1.530 & ---- & 1.5 & 1.49 \\
U-238 & .047 & .045 & ---- & .050 & .050 \\
Pu-239 & 1.64 & 1.65 & ---- & 1.65 & 1.64 \\
Pul-240 & .431 & .419 & --- & .446 & .446 \\
Pu-241 & 1.95 & 2.0 & --- & 1.97 & 1.96 \\
\hline
\end{tabular}

${ }^{\star}$ Five fission products, cycle time $=220$ days 
Table 2.4

One-Group Absorption Cross Sections

Zone 19 Reactor Center (Low Burnup)

\begin{tabular}{|c|c|c|c|c|c|}
\hline Nuclide & $\begin{array}{c}\text { ANL } \\
8 \text { Groups }\end{array}$ & $\begin{array}{l}\text { MIT } \\
10 \text { Groups } \\
\end{array}$ & $\begin{array}{l}\text { ORNL } \\
9 \text { Groups } \\
\end{array}$ & $\begin{array}{c}\text { BNL-1 } \\
50 \text { Groups }\end{array}$ & $\begin{array}{c}\text { BNL-2* } \\
50 \text { Groups }\end{array}$ \\
\hline$U-235$ & 1.86 & 1.91 & 1.85 & 1.87 & 1.86 \\
\hline$U-238$ & .225 & .235 & .219 & .221 & .226 \\
\hline Pu-239 & 1.86 & 1.90 & 1.85 & 1.87 & 1.86 \\
\hline$P u-240$ & .633 & .668 & .621 & .648 & .650 \\
\hline$P u-241$ & 2.24 & 2.30 & 2.23 & 2.25 & 2.24 \\
\hline F.P.** & .263 & .297 & .261 & .236 & .252 \\
\hline
\end{tabular}

Zone 32 Fast Region (High Burnup)

\begin{tabular}{|c|c|c|c|c|c|}
\hline Nuclide & $\begin{array}{c}\text { ANL } \\
\text { Groups }\end{array}$ & $\begin{array}{c}\text { MIT } \\
\text { 10 Groups }\end{array}$ & $\begin{array}{c}\text { ORNL } \\
\text { Groups }\end{array}$ & $\begin{array}{c}\text { BNL-1 } \\
50 \text { Groups }\end{array}$ & $\begin{array}{c}\text { BNL-2* } \\
50 \text { Groups }\end{array}$ \\
\hline U-235 & 1.83 & 1.89 & --- & 1.85 & 1.84 \\
U-238 & .226 & .234 & --- & .23 & .228 \\
Pu-239 & 1.88 & 1.92 & --- & 1.9 & 1.89 \\
Pu-240 & .731 & .716 & --- & .728 & .719 \\
Pu-241 & 2.23 & 2.29 & --- & 2.25 & .223 \\
F.P.** & .261 & .291 & --- & .231 & .244 \\
\hline
\end{tabular}

*Five fission products, cycle time $=220$ days $\star \star F i s s i o n$ Product 


\subsubsection{Comparisons in the Transition Fast to Epithermal Spectrum Region}

Table 2.5 compares the one-group fission cross sections for the transition zone (Zone 34 ). Inspection reveals that for the fissile isotopes, the differences range from a few percent to 25 percent. In particular, good agreement between the BNL-2, ANL and ORNL calculations is obtained upon replacing the earlier BNL-1 one-lump fission product cross section with the more explicit five fission products representation. These results indicate the sensitivity of the analysis to the fission product treatment and led to the study of fission product treatment to be reported in Section 3. As expected, the sensitivity of the fertile fission cross section is small due to the threshold nature of the cross section. In other words, the high energy component of the spectrum appears to be fairly insensitive to the differences between the methods and data utilized by the three participants.

Table 2.6 shows a comparison of the one-group absorption cross sections. With regard to the fissile isotopes, the trends observed for the fission cross sections are repeated to a large extent here. However, the differences are more pronounced with differences as high as $35 \%$. It should be noted that BNL-2 calculations are again in excellent agreenent with the ANL calculations.

With regard to the one-group fission product absorption cross section, the more explicit five-fission product treatment of BNL-2 is in good agreement with the ANL results. However, both the BNL-2 and ANL results are $23 \%$ lower than the URNL and MIT results. It is clear that any further comparisons must be based on a prescribed consistent fission product treatment. 
Table 2.5

One-Group Fission Cross Sections.

Zone 34 Transition Fast to Epithermal Spectrum Reyion

\begin{tabular}{|c|c|c|c|c|c|}
\hline Nuclide & $\begin{array}{c}\text { ANL } \\
\text { Groups }\end{array}$ & $\begin{array}{c}\text { MIT } \\
10 \text { Groups }\end{array}$ & $\begin{array}{c}\text { ORNL } \\
9 \text { Groups }\end{array}$ & $\begin{array}{c}\text { BNL-1 } \\
50 \text { Groups }\end{array}$ & $\begin{array}{c}\text { BNL- } 2^{\star} \\
50 \text { Groups }\end{array}$ \\
\hline U-235 & 3.03 & 3.40 & 2.96 & 3.40 & 3.04 \\
U-238 & .042 & .041 & .038 & .046 & .044 \\
Pu-239 & 2.68 & 3.36 & 2.69 & 3.09 & 2.68 \\
Pu-240 & .368 & .385 & .370 & .404 & .398 \\
Pu-241. & 4.39 & 5.35 & 4.74 & 5.47 & 4.6 \\
\hline
\end{tabular}

*Five fission products, cycle time $=220$ days

Table 2.6

One-Group Absorption Cross Sections

Zone 34 Transition Fast to Epithermal Spectrum Region

\begin{tabular}{|c|c|c|c|c|c|}
\hline Nuclide & $\begin{array}{c}\text { ANL } \\
\text { G Groups }\end{array}$ & $\begin{array}{c}\text { MIT } \\
10 \text { Groups }\end{array}$ & $\begin{array}{c}\text { ORNL } \\
9 \text { Groups }\end{array}$ & $\begin{array}{c}\text { BNL }-1 \\
50 \text { Groups }\end{array}$ & $\begin{array}{c}\text { BNL }-2^{\star} \\
50 \text { Groups }\end{array}$ \\
\hline U-235 & 4.09 & 4.68 & 4.09 & 4.67 & 4.17 \\
U-238 & .352 & .364 & .355 & .390 & .369 \\
Pu-239 & 3.72 & 4.95 & 3.82 & 4.41 & 3.79 \\
Pu-240 & 2.83 & 6.70 & .397 & 3.16 & 2.42 \\
Pu-241 & 5.40 & 6.00 & 5.86 & 6.75 & 5.63 \\
F.P.** & 1.30 & 1.6 & 1.6 & .871 & 1.29 \\
\hline
\end{tabular}

*Five fission products, cycle time $=220$ days **Fission product 


\subsubsection{Comparisons in the Epithermal Spectrum Region}

Tables 2.7 and 2.8 compare the one-group fission and absorption cross sections, respectively, for the epithermal region. As expected, the largest differences between the different calculational schemes will be manifested here. The results will be very sensitive to treatment in the resolved resonance region, spatial group collapsing, and group structure. Inspection of Table 2.7 shows that the differences between the various methods yleld differences as Iarce as $40 \%$ with the URNL calculations showing the largest difference when compared to the ANL, MIT and BNL calculations. The BNL and ANL calculations are in very close agreement, lending some confidence to the ANL yroup collapsing methods as far as epithermal fission is concerned.

Comparison of absorption (mainly capture) in the epitherilal region, as shown in Table 2.8, reveals some interesting points:

1. For the important isotope U-238, the MIT, ORNL and BNL calculations agree to within 4\%. The ANL calculations indicate a U-238 capture rate that is $20 \%$ lower than the others:

2. The ANL broad group set was obtained using the MC2 II/SDX systen which has an accurate resonance treatment based on RABBLE; the remaining treatments use the narrow resonance approximation (NRA). It is thus sonewhat puzzling that the one..group cross sections based on the NRA are higher than those based on an exact treatment, since one would expect the exact collision density to increase in the interior of a resonance yielding a higher cross section. The Pu-240 absorption cross section follows the expected trend, in that the one-group cross section corresponding to the exact calculation is higher than the cross section based on the NRA (see Table 2.8). 
Table 2.7

One-Group Fission Cross Sections

Zone 10 Epithermal Spectrum Region

\begin{tabular}{|c|c|c|c|c|c|}
\hline Nuclide & $\begin{array}{c}\text { ANL } \\
\text { Groups }\end{array}$ & $\begin{array}{c}\text { MIT } \\
\text { 10 Groups }\end{array}$ & $\begin{array}{c}\text { ORNL } \\
\text { Groups }\end{array}$ & $\begin{array}{c}\text { BNL-1 } \\
\text { Groups }\end{array}$ & $\begin{array}{c}\text { BNL-2 } \\
50 \text { Groups }\end{array}$ \\
\hline U-235 & 13.4 & 12.0 & 11.7 & 12.6 & 12.5 \\
U-238 & .035 & .039 & .028 & .034 & .033 \\
Pu-239 & 14.5 & 14.3 & 13.8 & 15.7 & 15.6 \\
Pu-240 & .342 & .332 & .292 & .354 & .350 \\
Pu-241 & 22.1 & 22.8 & 23.7 & 24.7 & 24.4 \\
\hline
\end{tabular}

*Five fission products, cycle time $=220$ days

Table 2.8

One-Group Absorption Cross Sections

Zone 10 Epithermal Spectrum Region

\begin{tabular}{|c|c|c|c|c|c|}
\hline Nuclide & $\begin{array}{c}\text { ANL } \\
8 \text { Groups }\end{array}$ & $\begin{array}{c}\text { MIT } \\
10 \text { Groups } \\
\end{array}$ & 9 GRNL & $\begin{array}{l}\text { BNL } \\
50 \text { Groups } \\
\end{array}$ & $\begin{array}{l}\text { BNL* } \\
50 \text { Groups }\end{array}$ \\
\hline$U-235$ & 17.9 & 16.6 & 16.3 & 17.3 & 17.3 \\
\hline$U-238$ & .556 & .646 & .665 & .673 & .669 \\
\hline$P u-239$ & 21.7 & 22.3 & 21.5 & 21.5 & 21.1 \\
\hline$P u-240$ & 102.4 & 40.4 & 92.2 & 82.0 & 72.6 \\
\hline$P u-241$ & 28.7 & 29.5 & 30.7 & 31.8 & 31.4 \\
\hline 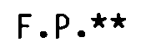 & 11.55 & 6.72 & 19.2 & 2.92 & 9.74 \\
\hline
\end{tabular}

*Five fission products, cycle time $=220$ days

**Fission product 
Based on the above comparison, it is seen that the differences in U-238 capture in the moderated zones are not entirely due to the NRA, which is usually the chief cause of differences in this energy band, but involve other factors. These factors include the number of broad groups and the choice of group boundaries. It is felt that the latter is particularly important in the moderated zone where individual resonances play an important role. This point will be discussed in the section on group collapsing. Finally, the U-238 capture cross section in the resonance range is particularly important in the FMSR, since it controls the enrichment of the fuel before it enters the fast part of the core.

3. For the fertile Pu-240 isotope, there is a wide range in values varying by as large as a factor of 2.55 , with the MIT values showing the largest deviation froln the others (approximately a factor of 2 lower than the average of the others).

4. For the fission product absorptions, there is reasonable agreement ( 20\%) between the ANI and KNI -) ralrulatinns. Howẹver, the lokNL results are approximately a factor of two higher and the MIT̈ results approximately $40 \%$ lower. Differences of the order of $20 \%$ are reasonable, but a factor of two indicates that some basic differences in treatment need to be resolved.

\subsubsection{Spectral Shift Effects}

A measure of the spatial dependence of the neutron spectrum is the spectral index. Such indices as the ratio of fissile to fertile fissions and the ratio of fertile capture to fertile fissions give the deyree of spectral softening or hardening, a high index corresponds to a soft spectruln and a sillall index to a hard spectrum. For comparison, a yas-cooled breeder using oxide fuel 
has a fissile to fertile ratio of 32 and a conventional LMFBR has an index of around 50 .

Table 2.9 gives a comparison of the spectral indices. Inspection shows the degree of spectrum softening with the indices varying by a factor of five from the fast to epithermal spectrum zones. For the Pu-239 fission to U-238 fission ratios, there is good agreenent in the fast region $(\sim 10 \%)$, poorer agreement in the transition region ( $30 \%)$ and epithermal regions $(\sim 20 \%)$. BNL and ANL calculations are in reasonably good agreement ( $10 \%)$. Similar conclusions can be drawn by comparing the U-235 to U-238 fission ratios.

For the important U-238 capture to U-238 fission ratios, good agreement $(10 \%)$ is observed for the fast region and transition regions $(\sim 12 \%)$. The ANL and BNL results are in excellent agreement. However, in the epithermal spectrum region, the ANL results are about $27 \%$ lower than the average of the BNL, MIT and ORNL results. These results are consistent with the one-group absorption cross section comparisons of Table 2.8 .

\subsubsection{Effect of Group Collapse on One-Group Cross Sections}

In order to gain some perspeetive on the effect of using fewer groups, a comparison was made between calculations using 10 and 50 groups. The BNL 50group library was collapsed to 10 groups using the 1DX code. Zone-wise cross

sections were obtained for four zones; namely, two for each fast zone, a transition zone, and the moderator zone. The ten-energy group structure is given in Table 2.10.

As expected, the cross sections in the fast region were rather insensitive to group structure. Table 2.11 presents the one-group cross sections for the transition and moderator zones. 
Table 2.9

Comparison of Spectral Indices

$$
\sigma_{f}^{239} / \sigma_{f}^{238}
$$

\begin{tabular}{|l|r|r|r|r|}
\hline Lab/Groups & ANL/8 & MIT/10 & ORNL/9 & \multicolumn{1}{c|}{ BNL/50 } \\
Fast & 34.9 & 36.7 & --- & 33.1 \\
Transition & 63.8 & 81.9 & 70.8 & 67.2 \\
Epithermal & 416.7 & 478.9 & 492.5 & 465.9 \\
\hline
\end{tabular}

$$
\sigma_{f}^{235} / \sigma_{f}^{238}
$$

\begin{tabular}{|l|r|r|r|r|}
\hline Lab/Groups & ANL/8 & MIT/10 & ORNL/9 & \multicolumn{1}{|c|}{ BNL/50 } \\
\hline Fast & 31.7 & 34.0 &.-- & 30.0 \\
Transition & 72.1 & 82.9 & 77.9 & 73.9 \\
Epitherma & 387.0 & 402.7 & 416.4 & 373.9 \\
\hline
\end{tabular}

$$
\sigma_{c}^{238} / \pi_{f}^{238}
$$

\begin{tabular}{|l|r|r|r|r|}
\hline Lab/Groups & ANL/8 & MIT/10 & ORNL/9 & BNL/50 \\
\hline Fast & 3.8 & 4.2 & --- & 3.6 \\
Transition & 7.4 & 7.9 & 8.3 & 7.5 \\
Epithermal & 15.0 & 20.7 & 22.8 & 19.0 \\
\hline
\end{tabular}

$$
\begin{array}{ll}
\text { GCFR Critical Experiment } & (9) \\
\sigma_{f}^{239} / \sigma_{f}^{238} & =32.4 \\
\text { 7FPR-? }(10) & \sigma_{f}^{235} / 0_{f}^{238}=50.0 \\
\text { JEZEBEL (Fast) }(11) & \sigma_{f}^{235} / \sigma_{f}^{238}=4.7
\end{array}
$$


Table 2.10

Group Structure for BNL 10-Group Library

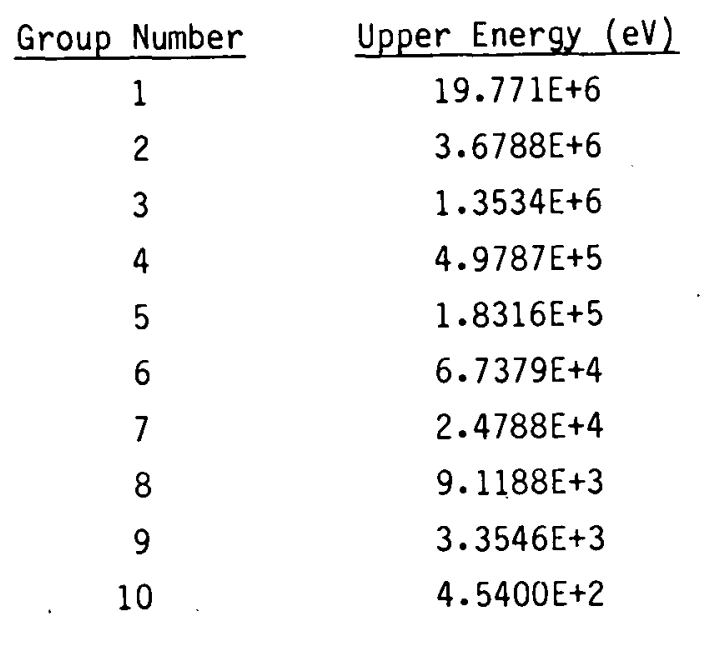


Table 2.11

Comparison of BNL 10-Group and 50-Group Calculations

ane-Group Cross Sections

\begin{tabular}{|c|c|c|c|c|c|c|c|}
\hline & \multicolumn{3}{|c|}{ 50 ENERGY GROUPS } & \multicolumn{4}{|c|}{10 ENEPGGY GROUPS } \\
\hline & \multirow{2}{*}{$\frac{\text { TRANSITIOM ZOME }}{\text { Fission }}$} & \multicolumn{2}{|c|}{ MODERATOR ZONE } & \multirow{2}{*}{\multicolumn{2}{|c|}{$\frac{\text { IRANSITION ZONE }}{\text { Fissior. }}$}} & \multicolumn{2}{|c|}{ MODERATOR ZONE } \\
\hline & & Fissicri & Absorption & & & Fission & Absorption \\
\hline U-235 & 3.4 & 12.6 & 17.3 & 3.5 & & 12.3 & 16.2 \\
\hline $\mathbb{U}-238$ & 0.046 & 0.034 & 0.673 & 0.047 & & 0.032 & 0.581 \\
\hline Pu-239 & 3.09 & 15.7 & 24.5 & 3.31 & & 16.7 & 25.3 \\
\hline Pu-240 & 0.404 & 0.354 & 82.0 & 0.497 & & 0.350 & 83.5 \\
\hline Pu-241 & 5.47 & 24.7 & 31.8 & 5.52 & . & 27.3 & 31.8 \\
\hline$\sigma_{c}^{238} / \sigma_{f}^{239}$ & & \multicolumn{2}{|c|}{3.041} & & & \multicolumn{2}{|c|}{0.033} \\
\hline$\alpha^{239}$ & & \multicolumn{2}{|c|}{0.56} & & & \multicolumn{2}{|c|}{0.52} \\
\hline$B R=\frac{0}{(1+0}$ & $\begin{array}{l}238 \\
\frac{c}{\sigma_{f}^{239}}\end{array}$ & \multicolumn{2}{|c|}{.026} & & & \multicolumn{2}{|c|}{0.022} \\
\hline
\end{tabular}


Examining Table 2.11, it is seen that the uranium cross sections show little sensitivity to group structure with the exception of the important absorption cross section for U-238, where in the moderator zone, there is a change of $14 \%$ in the capture cross section upon reducing the nurnber of yroups from 50 to 10 .

In the transition region, there appears to be a general change in the spectrum shape as evidenced by the increase in the fissile cross sections and an increase in the fertile fission cross sections.

In the moderator region, there is a somewhat contradictory behavior. While the fissile cross sections for the 10-yroup case are higher, the $\mathrm{U}-238$ capture cross section is lower. Also, the ratio of U-238 capture to Pu-23y fission decreases upon going from 50 to 10 groups and there is a slight decrease in the plutonium alpha. The only conclusions to be drawn froll this behavior are:

1. There is some spectrum softening upon reducing the number of groups from 50 to 10 .

2. The most pronounced effect, huwever, appears to be in the resonance capture treatment of $\mathrm{U}-238$.

3. The U-238 capture cross section is reduced, and tor the FMSR, this can have important and significant impact on the breeding in the moderator zone, inasmuch as this determines the enrichment of the fuel at time of shuffling to the fast region. 


\section{FISSION PRODUCTS}

\subsection{INTRODUCTION}

The treatment of fission products in the FMSR concept requires a different approach from that taken in analyzing conventional reactor designs for the following reasons:

a) The spectrum varies from extremely hard (harder than the GCFR) to conlparatively soft (with a substantial fraction of the neutrons in the resolved resonance range). Thus, the conventionally accepted fission product treatnients used for fast reactors or those used for power reactors are not directly applicable.

b) The long fuel exposure times required in the FMSR require more attention to the entire fission product chain, i.e., simple lumped fission product treatments as used in fast reactors are not sufficiently accurate.

c) The long fuel exposure times lead to production of a substantial amount of fission products. Due to the relatively high capture cross sections of these fission products, sufficient care and accuracy are required in their determination.

From the above, it is clear that the conventional treatments of fission products are not satisfactory. Several studies have been carried out to determine a more acceptable way of dealing with this problem. The following sections will outline the previously used one-lump model, the currently used model, and finally, work that is in progress on a two-lump model. 


\subsection{FISSION PRODUCT MODEL USED IN THE INITIAL FMSR FEASIBILITY STUDY}

The 50-group LIB-IV fission product cross-section library (7) was used in the Initial Feasibility Study. This set lumps all fission products into five groupings. (7) These are based on thermal reactor experience and are thus more consistent with a well-moderated spectrum. They are Xe-135, Sm-149, a Rapidly Saturating Lump (RSFP), a Slowly Saturating Lump (SSFP) and a Non-Saturating Lump (NSFP), for each fissionable isotope. Brookhaven's original treatment considered the non-saturating lump only and adjusted its cross sections by a multiplicative factor to account for the remainder of the fission products and the fact that two fission products are emitted per fission event. Since the cross sections for RSFP, SSFP, Xe-135 and Sm-149 are higher than the NSFP, this factor is customarily taken to be larger than 2; in fact, the actual value used was 2.7. In the fast zone of the FMSR this model is reasonably satisfactory and it also conforms with current fast reactor practice. However, in the moderated zones, it was found that this model failed to represent the fission products accurately. In order to estimate the magnitude of the possible error involved, a new fission product lump was defined. This lump was composed of a mixture of NSFP and SSFP in the approximate ratio of their yields, 1.6 to .4, respectively. Using this revised lump, the BOEC value of $\mathrm{k}_{\mathrm{e}}$ was lowered by $0.4 \%$ and the overall spectrum hardened, reflecting increased absorption in the resolved resonance range due to the explicit inclusion of the SSFP. The results of this calculation suggested a revision in the treatment of fission products and a departure from the one-lump model.

\subsection{CURRENTLY USED FISSION PRODUCT MODEL}

The current FMSR fission product treatment uses the full Garrison-Roos $(9)$ scheme recommended for use with ENDF/B-3 and implemented in the LIB-IV fast 
reactor library, albeit without scattering matrices for the lumps. This consists of the isotopes $\mathrm{Xe}-135$ and Sm-149 with scattering matrices and the three lumps as indicated in the previous section without scattering matrices. The composition of the lumps together with an estimate of their worth in the fast spectrum regions of an FMSR (based on the Kikuchi one-group fast reactor cross sections (8) are shown in Table 3.1. The effect of using the model on the FMSR can be seen in Figure 3.1 and can be summarized as follows:

1. The Xe-135 isotope was unimportant in describing the long-term reactivity effects in the FMSR.

2. Sm-149 and Sm-151 (which are the main constituents FMSR-wise of the rapidly saturating lump) are important in their anelioration of fuelmoderator interface power-peaking effects. Figure 3.1 and Table 3.1 both show that the non-saturating and the slowly-saturating lumps are the most important and are responsible for over $90 \%$ of the absorption in the bulk of the FMSR. However, the lumping and their descriptive titles of Garrison and Roos are based on the properties of the constituent nuclide in thermal reactor systems and are not meaningful in an FMSR (or LMFBR) context. Investigations to obtain more meaningful groupings are described in the next section.

\subsection{EFFECT OF SCATTERING MATRIX}

The previous model does not include a scattering matrix for any of the three lumped fission products. Scattering matrices were provided for samariun and xenon only; the other fission products were represented solely by their respective absorption cross section. Although such a representation may be acceptable for conventional FBR reactor designs where the percentage composition of fission products is comparatively low, it is inadequate for the FMSR where 
Table 3.1

Garrison-Roos Scheme

\begin{tabular}{|c|c|c|c|c|}
\hline I sotope & FMSR Ranking & Yield & Absorption (\%) & Total $(\%)$ \\
\hline$x e-135$ & --- & .0715 & .0003 & .0003 \\
\hline Sm-149 & 5 & .0130 & 5.16 & 5.16 \\
\hline$\underline{\mathrm{RS}}$ & & .0134 & & \\
\hline $\begin{array}{l}\text { Cd-113 } \\
\text { Sm-151 } \\
\text { Gd-155 } \\
\text { Gd-157 }\end{array}$ & $\begin{array}{c}--- \\
8 \\
-\cdots-\end{array}$ & & $\begin{array}{r}.04 \\
3.32 \\
.09 \\
.10\end{array}$ & 3.55 \\
\hline SS & & .4010 & & \\
\hline $\begin{array}{l}\text { Mo-95 } \\
\text { Tc-99 } \\
\text { Rh-103 } \\
\text { Xe-131 } \\
\text { Cs-133 } \\
\text { Nd-143 } \\
\text { Nd-145 } \\
\text { Pm-147 } \\
\text { Sm-152 } \\
\text { Eu-153 }\end{array}$ & $\begin{array}{r}12 \\
4 \\
2 \\
15 \\
6 \\
13 \\
17 \\
10 \\
\hdashline 16\end{array}$ & & $\begin{array}{l}1.73 \\
6.61 \\
7.31 \\
2.88 \\
6.33 \\
2.59 \\
2.29 \\
3.70 \\
.71 \\
1.85\end{array}$ & 36.01 \\
\hline \multicolumn{5}{|l|}{ NS } \\
\hline Rest & & 1.5011 & 55.28 & 55.28 \\
\hline
\end{tabular}




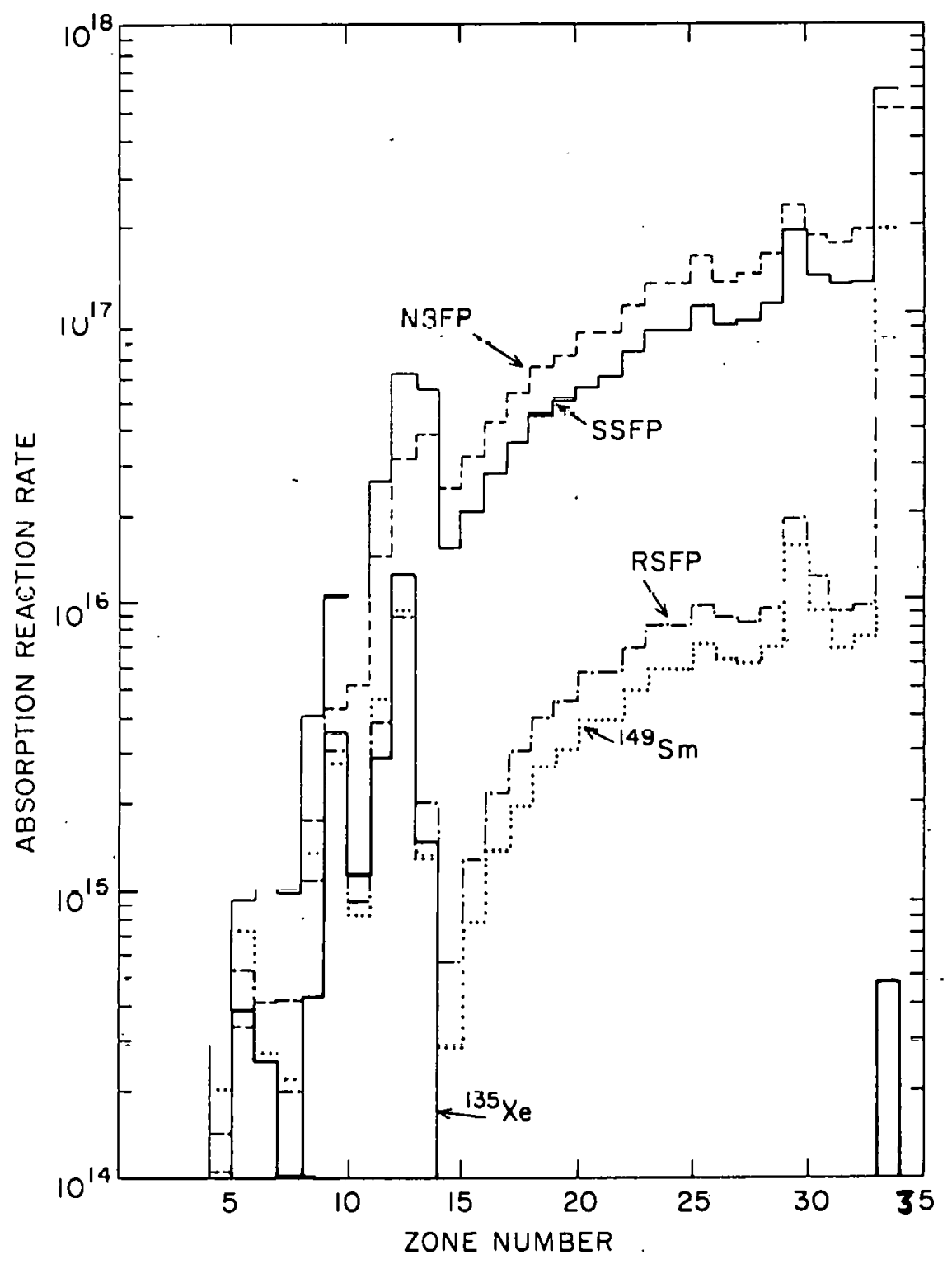

Figure 3.1. FMSR Fission Product Absorption History 
the fission product composition can be as high as $15 \%-20 \%$ of the discharge heavy metal. Such a large fission product fraction has a substantial effect on the neutron spectrum and thus the breeding ratio, cycle length and other performance characteristics. In order to investigate this effect, a scattering matrix for natural molybdenum was added for the three lumped fission products. The group total cross section of the revised lumps was adjusted to equal the sum of the fission product absorption and the molybdenum scattering cross sections. This approach is only approximate since the self-shielding factors for the new lumps cannot be corrected precisely. The implication of including a scattering matrix for all the fission product lumps was estimated by carrying out a simple calculation of an equilibrium cycle core. This calculation did not include the full series of calculations leading up to an equilibrium core cycle. The result of this calculation was a 1.4 percent reduction in keff which indicates that all new fission product evaluations should include explicit scattering matrices.

\subsection{CURRENT ACCURATE MODEL}

As was mentioned earlier, the existence of a wide range of spectra from very hard (harder than LMFBR) to softer than an oxide-fueled LMFBR, but harder than epithermal, plus the large buildup of fission products (of the order of $15 \%$ to $20 \%$ of the fuel at the end of 1 ife) results in the need for an accurate, burnup-dependent fission product lumping model that would be applicable to the wide range of spectra in the FMSR.

The proposed model consists of a two-lump fission product set, one based on the "odd-A" fission products and the other based on the "even-A" fission products, where " $A$ " is the atomic number of the fission product. The rationale for this model is based on the fact the "odd-A" isotopes' lumped microscopic 
absorption cross section is several times higher than the "even-A" isotopes' lumped microscopic cross section. This large difference in the lumped microscopic cross sections results in a higher rate of transfer of the "odd-A" isotopes to the "even-A" isotopes than vice versa. As a result, the rate of buildup of the "even-A" isotopes with burnup will be much faster than the "odd$A^{\prime \prime}$ isotopes. The net effect of this is a noticeably large drop in the total microscopic lumped fission product absorption cross section as a function of burnup. This drup which is baslcally due to the burnup dependence of the fission products cannot be predicted with a one-lump fission product model. The use of a nonburnup-dependent one-lump model can result in a substantial overestimation of the effective fission product absorption cross section at high burnups.

To study these effects and the behavior of the "two-lump" model, a detailed burnup analysis of 181 fission product elements in 84 chains was performed using a 154-group fission product library(10) (which was generated from the ENDFB/4 library) and the fission product code EPRI-CINDER. (11) The BNL analysis was carried out for two different spectra, one representing the "soft" spectrum zones of the FMSR (which includes moderator) and the other representing the "hard" spectrum zones of the FMSR. Figure 3.2 shows the neutron spectrum in the two representative zones. The fission product behavior was studied using the following procedure: Starting with the 154-group fission product 11brary for 181 el ements and the collapsing code TOAFEW, (10) two sets of four-group cross sections compatible with the EPRI-CINDER input format were generated for each of the above spectra. Next, the burnup dependence of the fission products in each spectrum was analyzed using the detailed 84 fission product chains. This "exact" behavior was then compared to the results of the 


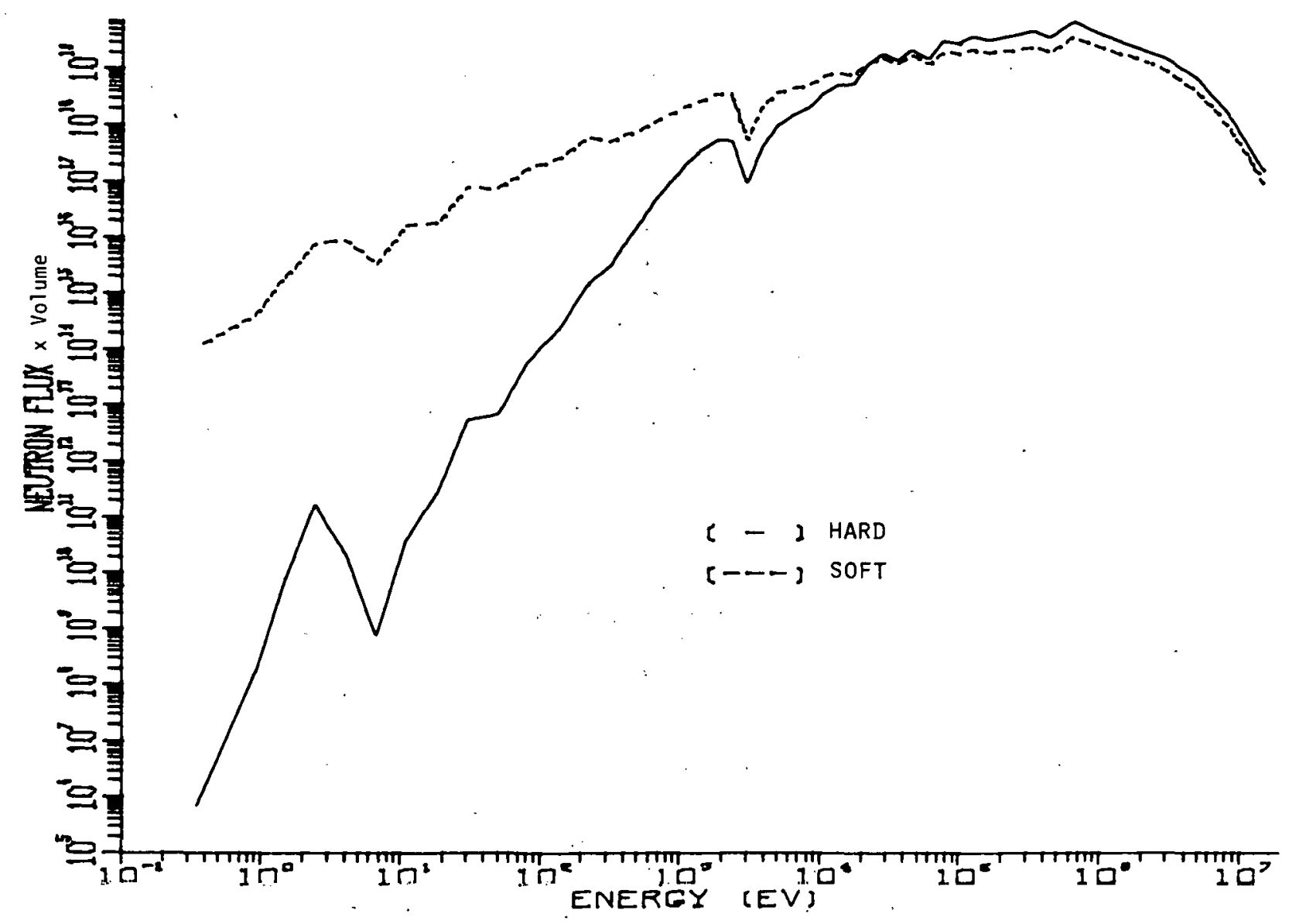

Figure 3.2. Representative FMSR Hard and Soft Spectra 


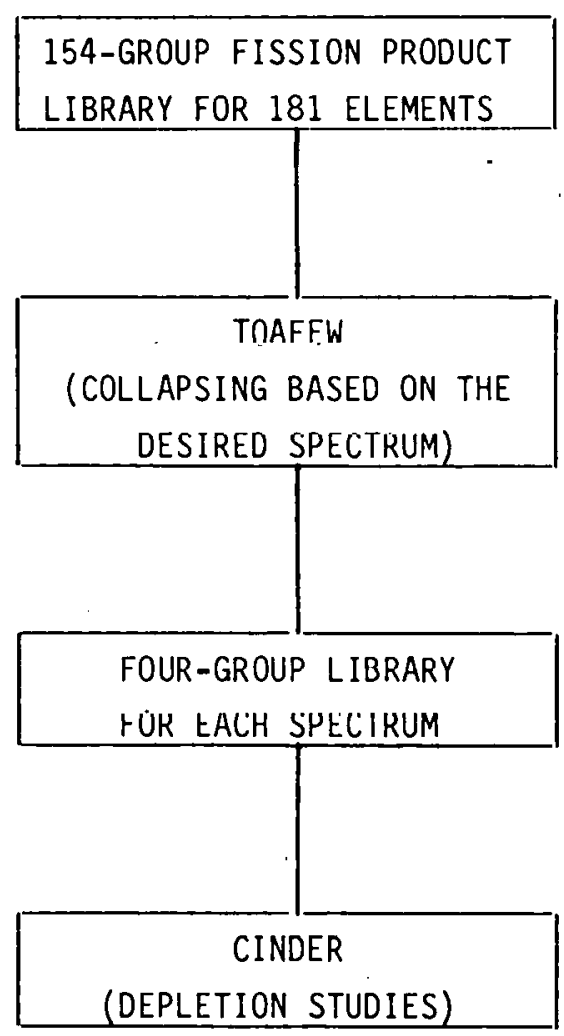

Figure 3.3. Sequence of Calcul.atinns Used in Fission Product Studies 
two-lump "odd-even" and other models such as the one-lump and Garrison-Roos model. Figure 3.3 shows the sequence of calculations described above.

Figure 3.4 shows the burnup dependence of the lumped fission product microscopic absorption cross section of the even-A, odd-A and all isotopes due to the fission of Pu-239 in the soft spectruin. As can be seen, the lumped microscopic absorption cross section of the "odd-A" isotopes is approximately four times higher than the "even-A" isotopes. Also, the lumped microscopic absorption cross section of the "even-A" isotopes goes through a very slow increase with burnup whereas the "odd-A" idotopes' lumped microscopic absorption cross section, after an initial jump (primarily due to xenon and samarium buildup), drops steadily. The net effect is a steadily declining lunped microscopic absorption cross section for all isotopes after the early peak has been passed. This drop is approximately $12.5 \%$ from the peak to 107,000 MWD/MT and $16.5 \%$ from the peak to 185,000 MWD/MT. The dashed line represents a "one-lump" microscopic cross section generated at 68,000 MWD/MT. The difference between the dashed line and the microscopic cross section for all isotopes represents the error that would be introduced in the microscopic absorption cross section if a onelump cross section at 68,000 MWD/MT is chosen to represent this burnup-dependent behavior.

As was mentioned earlier, the higher absorption cross section of the "odd$A$ " isotopes results in a higher rate of transfer of "odd-A" isotopes to "evenA" isotopes than vice versa. Consequently, the "even-A" isotopes' rate of buildup is higher than the "odd-A" isotopes, as is shown in Figure 3.5. This effect can be seen more clearly by looking at the odd and even fraction of the fission products produced as a function of burnup, shown in Figure 3.6. Note that, the total fission product adds up to two fission product isotopes per 


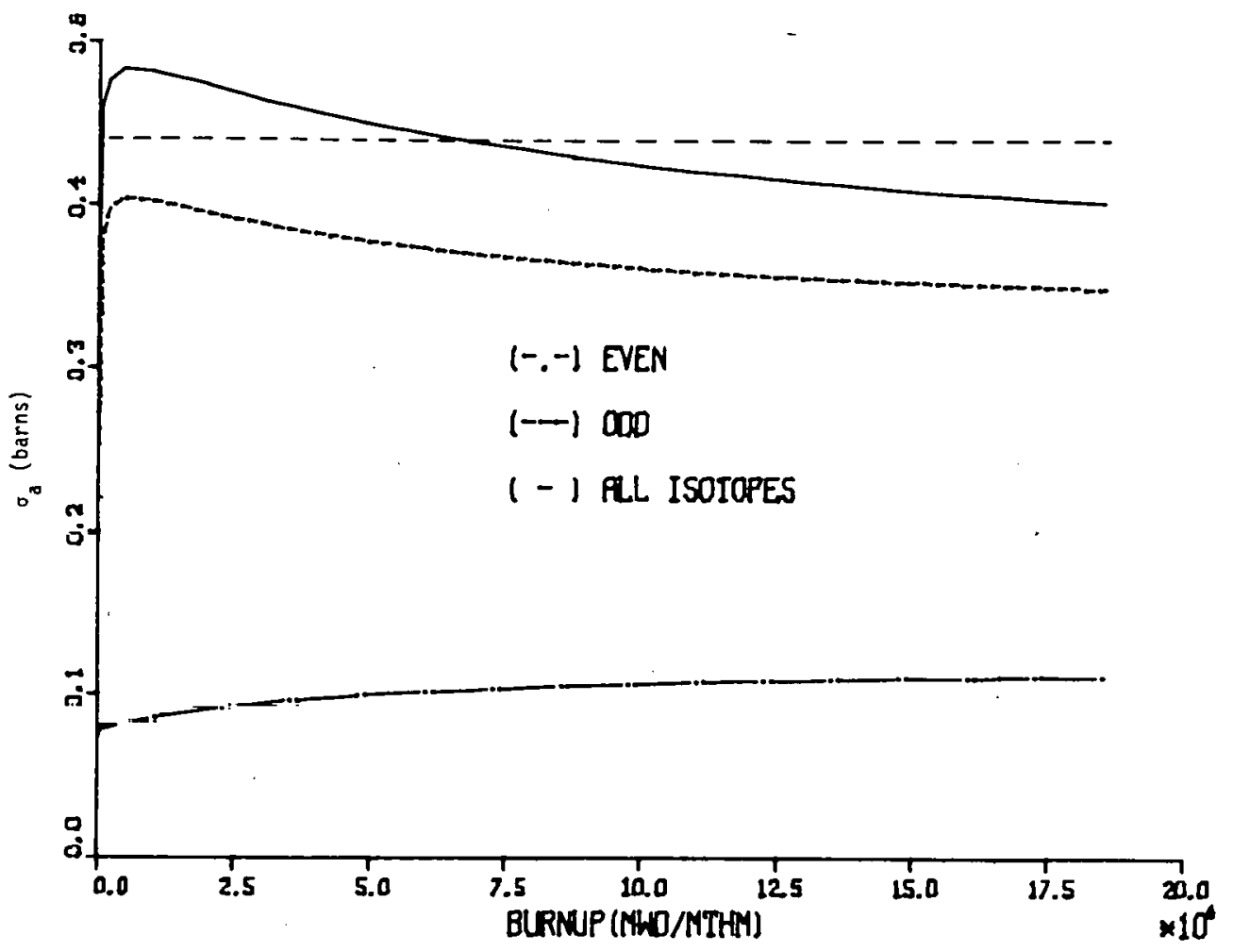

Figure 3.4. Lumped Fission Product Microscopic Absorption Cross Section of Odd-A, Even-A and All Isotopes Due to the Fission of $\mathrm{Pu}-239$ in the Soft Spectrum

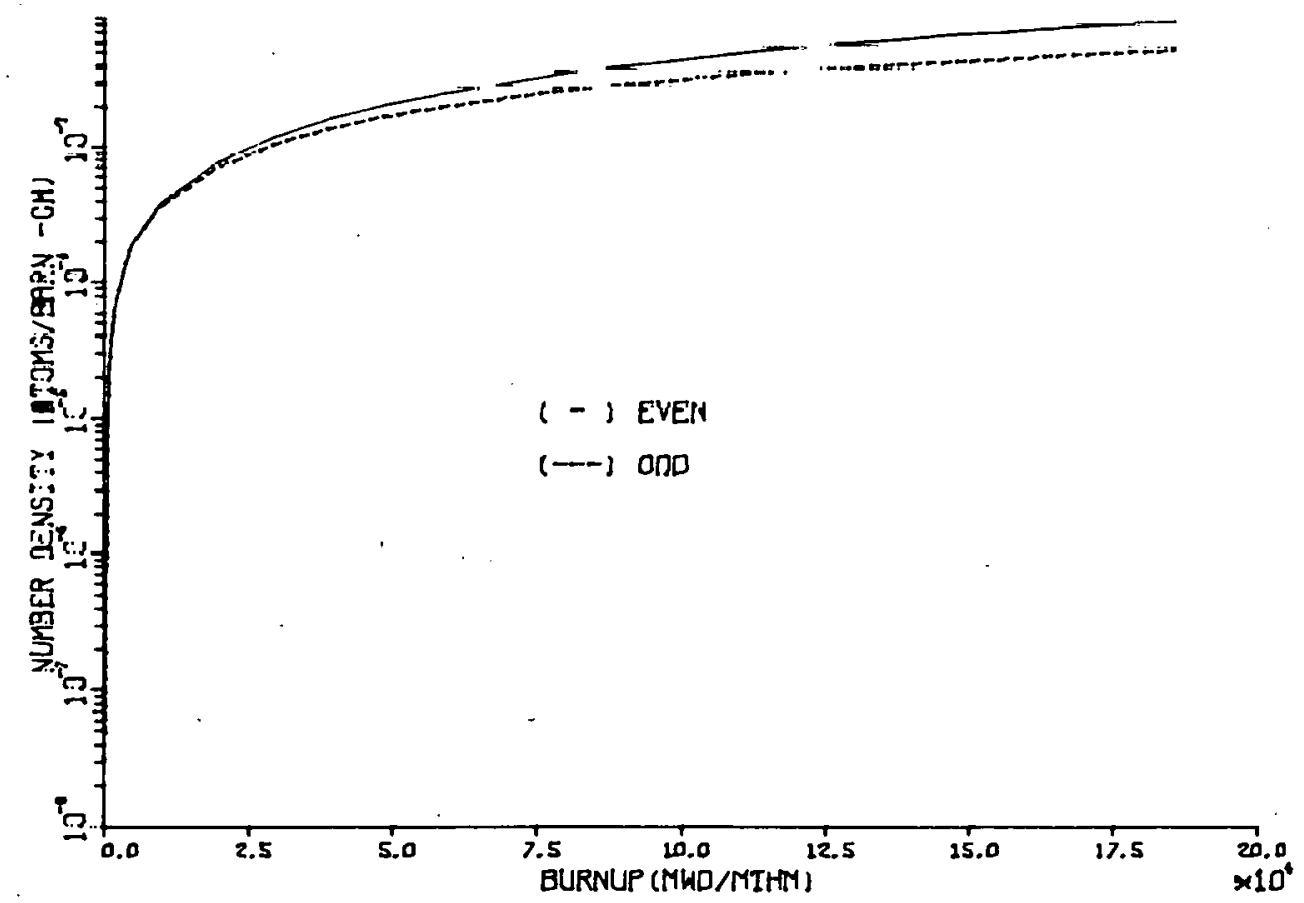

Figure 3.5. Even- and Odd-A Isotopes Buildup in the Soft Spectrum Zone as a Function of Burnup 


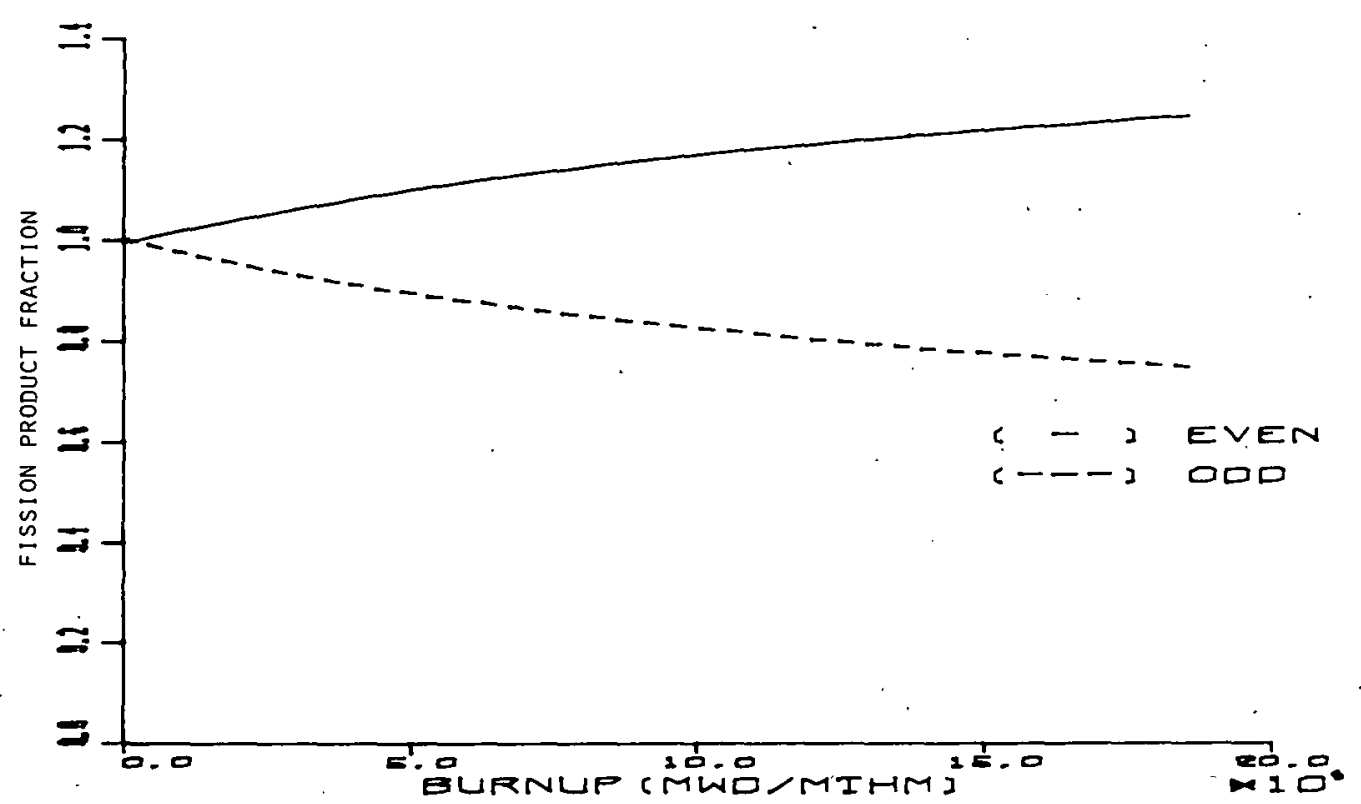

Figure 3.6. Even and Odd Fraction of Fission Products Due to Fission of Pu-239 in the Soft Spectrum as a Function of Burnup 
fission at all times. At the beginning of the burnup, the fractions of the even and odd isotopes are essentially the same, but as the fuel exposures increase, the fraction of the "even-A" isotopes increases and the fraction of the "odd-A" isotopes decreases. At 50,000 MWD/MT, the fractions of the odd- and even-A isotopes are 0.92 and 1.08 , respectively. At 100,000 MWD/MT, these fractions are 0.84 and 1.16 . At $150,000 \mathrm{MWD} / \mathrm{MT}$, these fractions change to 0.76 and 1.24. So it can be seen that the difference in the fractions of the even and odd isotopes increases substantially as a function of burnup.

To examine the behavior of the proposed "odd-even" model, thc dctailed burnup studies of the 84 chains of fission products, which are considered to be very close to the exact behavior of the fission products, were compared to the burnup characteristics of the two-lump model. In the two-lump model, a capture in an atom of the "odd-A" lump results in the production of an atom of the "even-A" lump and vice versa.

Table 3.2 compares the one-group lumped macroscopic absorption cross section of the detailed study labeled "exact" and the two-lump model. The onegroup lumped macroscopic absorption cross sections shown in Table 3.2 were generated by collapsing the four-group cross sections at each burnup step based on the specific zone spectrum. Before discussing the results of Table 3.2 , it should be noted that the initial odd and even four-group cross sections and yields are taken at the peak burnup point of the microscopic cross section curve. Looking back at Figure 3.4, it can be seen that there is an initial jump in the microscopic absorption cross section due to the saturation of the several chains (primarily the xenon and samarium chains). Unless these chains are explicitly represented, this initial jump cannot be expected to be reproduced by the two-lump model. Due to this fact, the initial four-group cross 
Table 3.2

Comparison Between the Lumped Macroscopic Absorption Cross Section - of the Exact and the Two-Lump "Odd-Even" Model (Cross Sections. Due to Pu-239 Fission in the Soft Spectrum Zone)

\begin{tabular}{|c|c|c|c|}
\hline $\begin{array}{c}\text { Burnup } \\
\text { (MWD/MT) }\end{array}$ & $\sum_{\substack{a \\
(\mathrm{~cm}-1)}}^{\text {Exact }}$ & $\sum_{(\mathrm{cm}-1)}^{2}$ Lump & $\begin{array}{c}\text { Difference } \\
(\%)\end{array}$ \\
\hline 0.78 & $0.992235-8$ & $0.145313-7$ & +46.0 \\
\hline 563.8 & $0.100000-4$ & $0.104520-4$ & +4.5 \\
\hline 1879.5 & $0.345387-4$ & $0.347583-4$ & +0.6 \\
\hline 4486.9 & $0.909663-4$ & $0.898903-4$ & -1.1 \\
\hline 9773.8 & $0.181202-3$ & $0.178246-3$ & -1.6 \\
\hline 19549.6 & $0.355755-3$ & $0.356319-3$ & -0.3 \\
\hline 29321.4 & $0.523704-3$ & $0.523441-3$ & -0.05 \\
\hline 39095.2 & $0.686307-3$ & $0.701950-3$ & +2.2 \\
\hline 48869.0 & $0.844479-3$ & $0.859262-3$ & +1.7 \\
\hline 58642.8 & $0.998891-3$ & $0.101227-2$ & +1.3 \\
\hline 68416.7 & $0.115005-2$ & $0.116129-2$ & +0.9 \\
\hline 78190.5 & $0.129835-2$ & $0.131777-2$ & +1.4 \\
\hline 87964.3 & $0: 144409-2$ & $0.147352-2$ & +2.0 \\
\hline 97738.1 & $0.158851-2$ & $0.162023-2$ & +1.9 \\
\hline 107511.9 & $0.172883-2$ & $0.175561-2$ & +1.5 \\
\hline 117288.7 & $0.186819-2$ & $0.188837-2$ & +1.0 \\
\hline 127059.6 & $0.200572-2$ & $0.201870-2$ & +0.6 \\
\hline 136833.4 & $0.214155-2$ & $0.214679-2$ & +0.2 \\
\hline 146607.2 & $0.227576-2$ & $0.227796-2$ & +0.09 \\
\hline 156381.0 & $0.240840-2$ & $0.240235-2$ & -0.2 \\
\hline 166154.8 & $0.253965-2$ & $0.252496-2$ & -0.5 \\
\hline 175928.6 & $0.266944-2$ & $0.264593-2$ & -0.8 \\
\hline 185702.5 & $0.279786-2$ & $0.276536-2$ & -1.1 \\
\hline
\end{tabular}


sections and yields for the odd and even lumps were normalized at the peak point of this curve. This procedure will result in an overprediction of the absorption cross section at the beginning of the fuel exposure. But, since the fission product abundance is very small at these initial small burnups, the error introduced by this overprediction at the beginning of burnup should be very smal1. Work is currently under way to introduce one or two explicit chains along with the two lumps to see if this initial jump can be reproduced. Looking back at Table J.2, il can be seen Lhat the two-lump model cann predict the burnup behavior of the exact treatment very closely. The maximum deviation of the two-lump model from the exact treatment over the 185,000 MWD/MT of burnup is about $2 \%$. This is essentially the type of accuracy that is extrenely desirable for the FMSR calculations due to the large fission product buildup.

An exercise was performed to examine how well this burnup dependence of the fission products can be predicted using a one-lump model. A set of lumped four-group cross sections was generated at $68,000 \mathrm{MWD} / \mathrm{MT}$. The choice of the burnup point at which the one-lump cross-section set is generated depends on the length of burnup cycle and the burnup behavior of the fission products. In this case the 68,000 MWD/MT was chosen to represent the middle of a burnup cycle of the order of $14 \%$ to $15 \%$ exposure. The results are shown in Table 3.3 for Pu-239 fission in the soft spectrum zone. The results show that the onelump model underpredicts the macroscopic absorption cross section hy as much as $9 \%$ in the early part of fuel exposure up to 68,000 MWD/MT and then it overpredicts the absorption by about $12 \%$ at 185,000 MWD/MT.

A comparison was also made between the detailed treatment and the Garrison-Roos treatment currently included in the LIB-IV cross-section library. The results are given in Table 3.4 and are plotted in Figure 3.7 . It can be seen 
Table 3.3

Comparison Between the Lumped Macroscopic Absorption Cross Section of the Exact and the One-Lump Model Generated at 68,000 MWD/MT

(Cross Sections due to Pu-239 Fission in the Soft Spectrum Zone)

\begin{tabular}{|c|c|c|c|}
\hline $\begin{array}{c}\text { Burnup } \\
\text { (MWD/MT) }\end{array}$ & $\sum_{(\mathrm{cm}-1)}^{\text {Exact }}$ & $\sum_{a}^{1}{ }_{\left(c m^{-1}\right)}$ & $\begin{array}{c}\text { Difference } \\
(\%)\end{array}$ \\
\hline 0.78 & $0.992235-8$ & $0.132654-7$ & +33.0 \\
\hline 563.8 & $0.100000-4$ & $0.955112-5$ & -4.4 \\
\hline 1879.5 & $0.345387-4$ & $0.318370-4$ & -7.8 \\
\hline 4486.9 & $0.909663-4$ & $0.827758-4$ & -9.0 \\
\hline 9773.8 & $0.181202-3$ & $0.165551-3$ & -8.6 \\
\hline 19549.6 & $0.355755-3$ & $0.331098-3$ & -6.9 \\
\hline 29321.4 & $0.523704-3$ & $0.496645-3$ & -5.1 \\
\hline 39095.2 & $0.686307-3$ & $0.662189-3$ & -3.5 \\
\hline 48869.0 & $0.844479-3$ & $0.827736-3$ & -1.9 \\
\hline 58642.8 & $0.998891-3$ & $0.993284-3$ & -0.5 \\
\hline 68416.7 & $0.115005-2$ & $0.115883-2$ & +0.7 \\
\hline 78190.5 & $0.129835-2$ & $0.132437-2$ & +2.0 \\
\hline 87964.3 & $0.144409-2$ & $0.148992-2$ & +3.1 \\
\hline 97738.1 & $0.158851-2$ & $0.165546-2$ & +4.2 \\
\hline 107511.9 & $0.172883-2$ & $0.182102-2$ & +5.3 \\
\hline 117288.7 & $0.186819-2$ & $0.198655-2$ & +6.3 \\
\hline 127059.6 & $0.200572-2$ & $0.215210-2$ & +7.2 \\
\hline 136833.4 & $0.214155-2$ & $0.231765-2$ & +8.2 \\
\hline 146607.2 & $0.227576-2$ & $0.248320-2$ & +9.1 \\
\hline 156381.0 & $0.240840-2$ & $0.264487-2$ & +9.9 \\
\hline 166154.8 & $0.253965-2$ & $0.281429-2$ & +10.8 \\
\hline 175928.6 & $0.266944-2$ & $0.297983-2$ & +11.6 \\
\hline 185702.5 & $0.279786-2$ & $0.314540-2$ & +12.4 \\
\hline
\end{tabular}


Table 3.4

Comparison Between the Lumped Macroscopic Absorption Cross Section of the Exact and the Garrison-Roos Model (Cross Sections Due to $\mathrm{Pu}-239$ Fission in the Soft Spectrum Zone)

\begin{tabular}{|c|c|c|c|}
\hline $\begin{array}{c}\text { Rurnu!p } \\
\text { (MWD/MT) }\end{array}$ & $\sum_{a}^{\text {Exact }}$ & $\sum_{\left(\mathrm{cm}^{-1}\right)}^{\text {Garrison-Roos }}$ & $\begin{array}{c}\text { Difference } \\
(\%)\end{array}$ \\
\hline 0.78 & $0.992235-8$ & $0.215323-7$ & +117.0 \\
\hline 563.8 & $0.100000-4$ & $0.154558-4$ & +54.0 \\
\hline 1879.5 & $0.345387-4$ & $0.551594-4$ & +59.0 \\
\hline 4486.9 & $0.909663-4$ & $0.130990-3$ & +43.0 \\
\hline 9773.8 & $0.181202-3$ & $0.256034-3$ & +41.0 \\
\hline 19549.6 & $0.355755-3$ & $0.492151-3$ & +38.0 \\
\hline 29321.4 & $0.523704-3$ & $0.714641-3$ & +36.0 \\
\hline 39095.2 & $0.686307-3$ & $0.927618-3$ & +35.0 \\
\hline 48869.0 & $0.844479-3$ & $0.113388-?$ & +34.0 \\
\hline 58642.8 & $0.998891-3$ & $0.133518-2$ & +33.0 \\
\hline 68416.7 & $0.115005-2$ & $0.153268-2$ & 133.0 \\
\hline 78190.5 & $0.129835-2$ & U.1/2/2L-2 & +33.0 \\
\hline 87964.3 & $0.144409-2$ & $0.191931-2$ & +32.0 \\
\hline 97738.1 & $0.158851-2$ & $0.210930-2$ & +32.0 \\
\hline 107511.9 & $0.172883-2$ & $0.229740-2$ & +32.0 \\
\hline 117288.7 & $0.186819-?$ & $0.248375=2$ & +32.0 \\
\hline 127059.6 & $0.200572-2$ & $0.266842-2$ & +33.0 \\
\hline 136833.4 & $0.214155-2$ & $0.285172-2$ & +33.0 \\
\hline 146607.2 & $0.227576-2$ & $0.303313-2$ & +33.0 \\
\hline 156381.0 & $0.240840-2$ & $0.321293-2$ & +33.0 \\
\hline 166154.8 & $0.253965-2$ & $0.339110-2$ & +33.0 \\
\hline 175928.6 & $0.266944-2$ & $0.356801-2$ & +33.0 \\
\hline 185702.5 & $0.279786-2$ & $0.374284-2$ & +33.0 \\
\hline
\end{tabular}


that the Garrison-Roos treatment consistently overpredicts the macroscopic absorption cross section by over $30 \%$. This result suggests that the fission product contribution to sodium void calculations in LMFBR calculations using the popular Garrison-Roos procedure may be overly pessimistic.

A similar study was performed for the fast region (hard spectrum) of the core where the detailed treatment of the fission products was compared to the proposed two-lump model. Figure 3.8 shows the behavior of the "exact" microscopic cross section due to fission of Pu-239 in the hard spectrum as a function of burnup. It should be noted that the spectrum of the representative fast zone is harder than a typical LMFBR spectrum due to the existence of metal fuel instead of oxide fuel. In Figure 3.8 the drop from the peak to 102,000 MWD/MT is $6.3 \%$ and the corresponding drop from the peak to 185,000 MWD/MT is $10.4 \%$.

Table 3.5 shows the comparison between the one-group lumped macroscopic absorption cross section generated using the "exact" treatment and the twolump model. As can be seen, the maximum difference is about $2.3 \%$ at 185,000 MWD/MT. Results of the comparison between the detailed treatment and a onelump model generated at 68,000 MWD/MT are given in Table 3.6. Note again that the error varies from a $5 \%$ underprediction to about a $7 \%$ overprediction. Table 3.7 shows the comparison between the detailed and Garrison-Roos treatment. Note again that the Garrison-Roos treatment consistently overpredicts the absorption by approximately $28 \%$.

The results of Tables 3.6 and 3.7 are very. important with respect to the LMFBR calculations. These results show that even in a spectrum that is harder than a typical LMFBR and, consequently, has a lower absorption cross section drop with burnup, the error in using a one-lump cross section is quite large. 


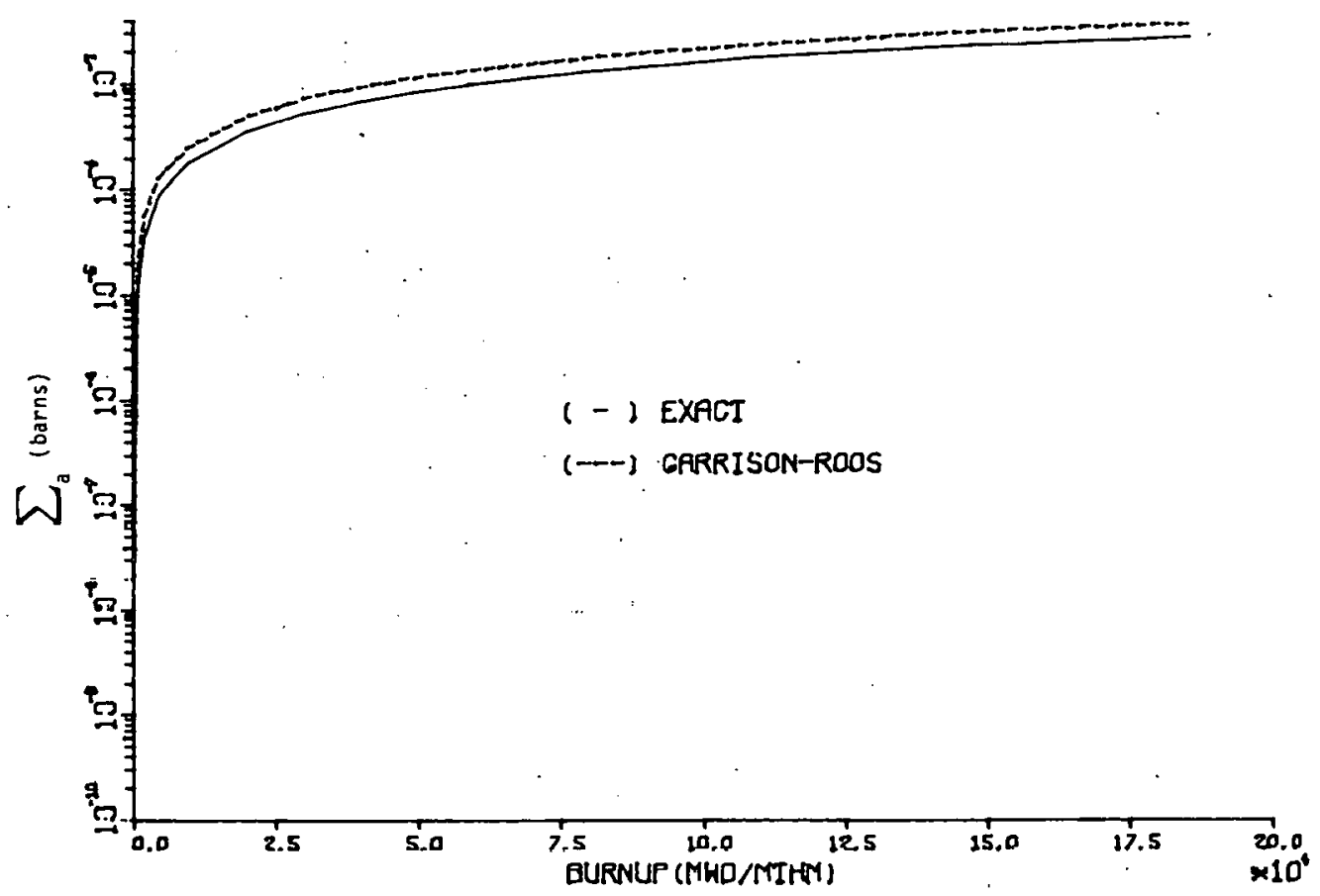

Figure 3.7. One-Lumped Macroscopic Cross Section Based on the Exact and Garrison-Roos Treatment as Function of Burnup

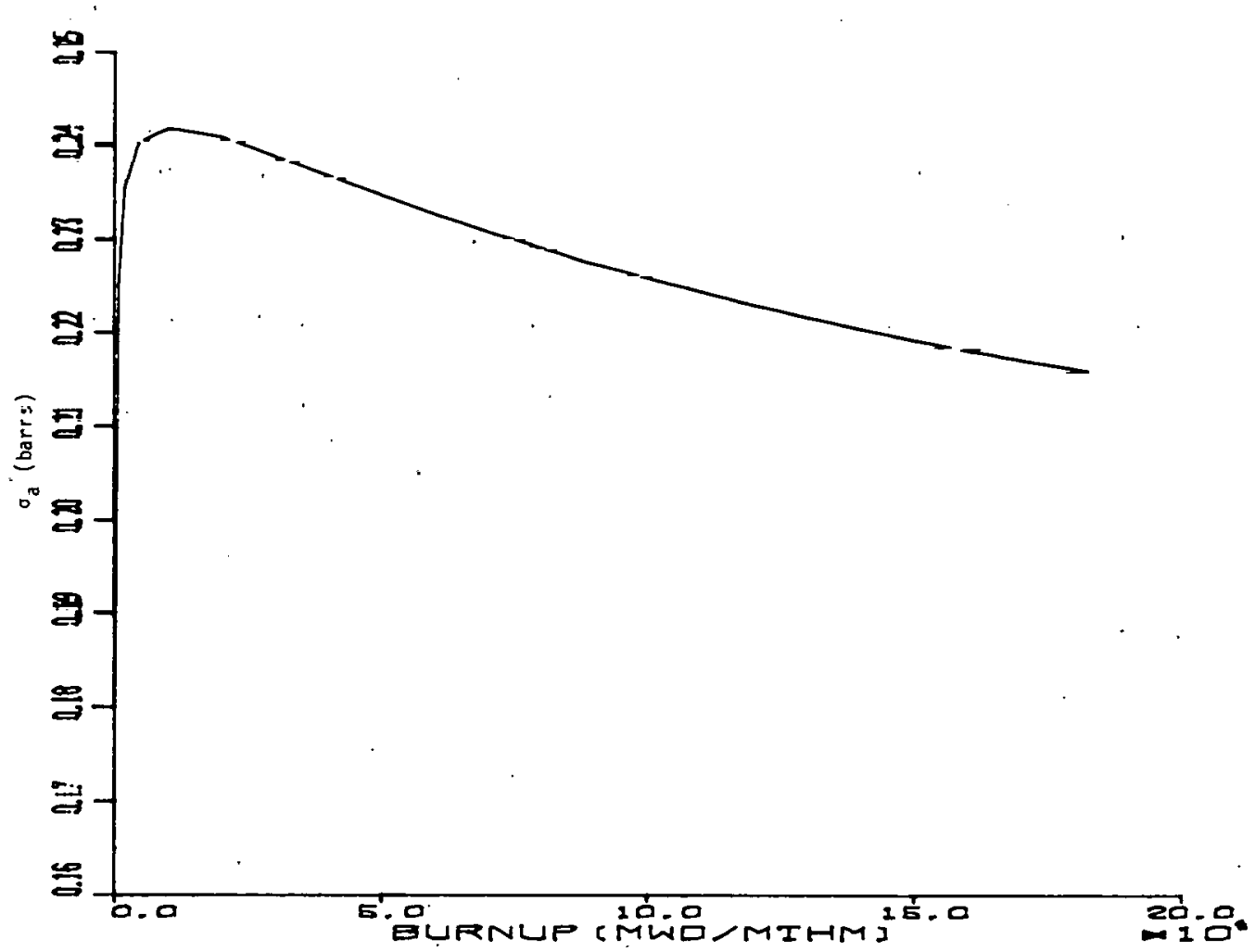

Figure 3.8. Lumped Microscopic Cross Section of Fission Products Due to $\mathrm{Pu}-239 \mathrm{Fission}$ in the Hard Spectrum 
Comparison Between the Lumped Macroscopic Absorption Cross Section of the Exact and Two-Lump Model (Cross Sections Due to Pu-239 Fission in the Hard Spectrum Zone)

\begin{tabular}{|c|c|c|c|}
\hline $\begin{array}{c}\text { Burnup } \\
\text { (MWD/MT) }\end{array}$ & $\sum_{\left(\mathrm{cm}^{-1}\right)}^{\text {Exact }}$ & $\sum_{\left(\mathrm{cm}^{-1}\right)}$ & $\begin{array}{c}\text { Difference } \\
(\%)\end{array}$ \\
\hline 0.78 & $0.498830-8$ & $0.727433-8$ & +45.0 \\
\hline 563.8 & $0.489729-5$ & $0.523471-5$ & +6.8 \\
\hline 1879.5 & $0.170867-4$ & $0.174272-4$ & +1.9 \\
\hline 4486.9 & $0.453672-4$ & $0.451817-4$ & -0.4 \\
\hline 9773.8 & $0.912053-4$ & $0.899484-4$ & -1.3 \\
\hline 19549.6 & $0.181583-3$ & $0.178266-3$ & -1.8 \\
\hline 29321.4 & $0.270117-3$ & $0.266030-3$ & -1.8 \\
\hline 39095.2 & $0.356896-3$ & $0.350310-3$ & -1.8 \\
\hline 48869.0 & $0.442047-3$ & $0.434171-3$ & -1.7 \\
\hline 58642.8 & $0.525785-3$ & $0.516677-3$ & -1.7 \\
\hline 68416.7 & $0.608182-3$ & $0.597889-3$ & -1.7 \\
\hline 78190.5 & $0.689378-3$ & $0.677872-3$ & -1.6 \\
\hline 87964.3 & $0.769478-3$ & $0.756668-3$ & -1.6 \\
\hline $97738: 1$ & $0.848576-3$ & $0.834346-3$ & $-1 \cdot 6=$ \\
\hline 107511.9 & $0.926752-3$ & $0.910941-3$ & -1.7 \\
\hline 117288.7 & $0.100407-2$ & $0.096505-3$ & -1.7 \\
\hline 127059.6 & $0.108060-2$ & $0.106110-2$ & -1.8 \\
\hline 136833.4 & $0.115640-2$ & $0.113474-2$ & -1.8 \\
\hline 146607.2 & $0.123151-2$ & $0.120749-2$ & -1.9 \\
\hline 156381.0 & $0.130598-2$ & $0.127938-2$ & -2.0 \\
\hline 166154.8 & $0.137985-2$ & $0.135048-2$ & -2.1 \\
\hline 175928.6 & $0.145 .314-2$ & $0.142080-2$ & -2.2 \\
\hline 185702.5 & $0.152590-2$ & $0.149034-2$ & -2.3 \\
\hline
\end{tabular}


Table 3.6

Comparison Between the Lumped Macroscopic Absorption Cross Section of the Exact and the One-Lump Model Generated at 68,000 MWD/MT

(Cross Sections Due to Pu-239 Fission in the Hard Spectrum Zone)

\begin{tabular}{|c|c|c|c|}
\hline $\begin{array}{l}\text { Burnup } \\
\text { (MWD/MT) }\end{array}$ & $\sum_{\left(\mathrm{cm}^{-1}\right)}^{\text {Exact }}$ & $\sum_{\left(\mathrm{cm}^{-1}\right)}$ & $\begin{array}{c}\text { Difference } \\
\langle \%\rangle\end{array}$ \\
\hline 0.78 & $0.498830-8$ & $0.693683-8$ & +39.00 \\
\hline 563.8 & $0.489729-5$ & $0.499450-5$ & +2.00 \\
\hline 1879.5 & $0.170867-4$ & $0.166483-4$ & -2.56 \\
\hline 4486.9 & $0.453672-4$ & $0.432856-4$ & -4.58 \\
\hline 9773.8 & $0.912053-4$ & $0.865711-4$ & -5.08 \\
\hline 19549.6 & $0.181583-3$ & $0.173141-3$ & -4.64 \\
\hline 29321.4 & $0.270117-3$ & $0.259711-3$ & -3.85 \\
\hline 39095.2 & $0.356896-3$ & $0.346280-3$ & -2.97 \\
\hline 48869.0 & $0.442047-3$ & $0.432852-.3$ & -2.08 \\
\hline 58642.8 & $0.525785-3$ & $0.519421-3$ & -1.14 \\
\hline 68416.7 & $0.608182-3$ & $0.605992-3$ & -0.30 \\
\hline 78190.5 & $0.689378-3$ & $0.692561-3$ & +0.40 \\
\hline 87964.3 & $0.769478-3$ & $0.779133-3$ & +1.25 \\
\hline 97738.1 & $0.848576-3$ & $0.865702-3$ & +2.01 \\
\hline 107511.9 & $0.926752-3$ & $0.952273-3$ & +2.76 \\
\hline 117288.7 & $0.100407-?$ & 0.103884-2 & +3.46 \\
\hline 127059.6 & $0.108060-2$ & $0.112541-2$ & +3.70 \\
\hline 136833.4 & $0.115640-2$ & $0.121198-2$ & +4.80 \\
\hline 146607.2 & $0.123151-2$ & $0.129855-2$ & +5.44 \\
\hline 156381.0 & 0.130598 .2 & $0.138512-2$ & +6.06 \\
\hline 166154.8 & $0.137985-2$ & $0.147169-2$ & +6.65 \\
\hline 175928.6 & $0.145314-2$ & $0.155826-2$ & +7.23 \\
\hline 185702.5 & $0.152590-2$ & $0.164483-2$ & +7.79 \\
\hline
\end{tabular}




\section{Table 3.7}

Comparison Between the Lumped Macroscopic Absorption Cross Section of the Exact and the Garrison-Roos Model (Cross Sections Due to Pu-239 Fission in the Hard Spectrum Zone)

\begin{tabular}{|c|c|c|c|}
\hline $\begin{array}{l}\text { Burnup } \\
\text { (MwD/MT) }\end{array}$ & $\sum_{a}^{\text {Exact }}$ & $\sum_{\mathrm{a}}^{\text {Garrison- }}\left(\mathrm{cm}^{-1}\right)$ & $\begin{array}{c}\text { Difference } \\
(\%)\end{array}$ \\
\hline 0.78 & $0.498830-8$ & $0.985911-8$ & +97.0 \\
\hline 563.8 & $0.489729-5$ & $0.709039-5$ & +44.0 \\
\hline 1879.5 & $0.170867-4$ & $0.235717-4$ & +37.0 \\
\hline 4486.9 & $0.453672-4$ & $0.609219-4$ & +34.0 \\
\hline 9773.8 & $0.912053-4$ & $0.120712-3$ & +32.0 \\
\hline 19549.6 & $0.181583-3$ & $0.237255-3$ & +30.0 \\
\hline 29321.4 & $0.270117-3$ & $0.350303-3$ & +29.0 \\
\hline 39095.2 & $0.356896-3$ & $0.460409-3$ & +29.0 \\
\hline 48869.0 & $0.442047-3$ & $0.568031-3$ & +28.0 \\
\hline 58642.8 & $0.525785-3$ & $0.673547-3$ & +28.0 \\
\hline 68416.7 & $0.608182-3$ & $0.777268-3$ & +27.0 \\
\hline 78190.5 & $0.689378-3$ & $0.879453-3$ & +27.0 \\
\hline 87964.3 & $0.769478-3$ & $0.980314-3$ & +27.0 \\
\hline 97738.1 & $0.848576-3$ & $0.108751-2$ & +27.0 \\
\hline 107511.9 & $0.926752-3$ & $0.118610-2$ & +27.0 \\
\hline 117288.7 & $0.100407-2$ & $0.128381-2$ & +27.0 \\
\hline 127059.6 & $0.108060-2$ & $0.138773-2$ & +28.0 \\
\hline 136833.4 & $0.115640-2$ & $0.148384-2$ & +28.0 \\
\hline 146607.2 & $0.123151-2$ & $0.157930-2$ & +28.0 \\
\hline 156381.0 & $0.130598-2$ & $0.167417-2$ & +28.0 \\
\hline 166154.8 & $0.137985-2$ & $0.176850-2$ & +28.0 \\
\hline 175928.6 & $0.145314-2$ & $0.186232-2$ & +28.0 \\
\hline 185702.5 & $0.152590-2$ & $0.196677-2$ & +28.0 \\
\hline
\end{tabular}


This leads to the conclusion that a more detailed, burnup-dependent lumping model such as the proposed odd-even model is also necessary for the fast reactor studies.

All the results reported so far have been for the Pu-239 fission in the "soft" and "hard" spectra. Similar studies were performed for U-235 and U-238 fission in both spectra. The conclusions were very similar to the ones stated above. The one-lump and Garrison-Roos treatment substantially overpredict the absorption at high burnups. The two-lump burnup-dependent. "odd-even" model can follow the exact behavior within approximately $2 \%$.

\subsection{CONCLUSIONS}

The following conclusions can be drawn from the study to date:

a) The initial one-lump model may be an inadequate representation for the entire reactor, being valid only in the fast core.

b) The currently used groupings (Sm-149, RSFP, SSFP and NSFP) are based on thermal reactor experience. (Quantities such as yields are characteristic of thermal fission.) In addition, nn explicit. srattering matrix is provided in the LIB-IV library for the three lumped fission products. These are considered disadvantages of the Garrison-Roos model in the FMSR application.

c) In comparing the one-lump and Garrison-Roos treatment with the "exact" behavior, it. was found that both models substantially overpredict the fission product absorption at high burnups. This could lead to, among other effects, an overprediction of the sodium void coefficient at high burnups. 
d) In view of the above mentioned shortcomings of the currently used model, a new two-lump burnup-dependent "odd-even" model was developed. This model is capable of predicting the "exact" behavior of fission product absorption as a function of burnup over a wide range of spectra with a maximum error of approximately $2 \%$. Based on this it has been decided to adopt the two-lump model as the basic fission product lumping model for the FMSR calculations. Work is currently under way to generate a multigroup lumped fission product library which includes a complete downscattering matrix. 


\section{CONCLUSIONS}

The FMSR benchmark served a very useful purpose in that it provided a mechanism for comparing state of the art calculations and data. In particular, it provided more stringent comparisons vis-a-vis the standard FBR benchmarks. This is due to the large spectral variations in the FMSR.

The primary conclusions from the benchmark activities are:

1. For the reference design, ovcrull agreement between the participating calculations was reasonable for parameters such as eigenvalue and breeding ratio. For the equilibrium BOEC and EOEC, the results agreed to within $1.5 \%$ in $k_{e}$, with ANL showing the largest deviation from the average.

2. Of all the effects studied, the treatment of fission product cross sections is clearly the most important contributor to the observed differences. This led BNL lu implemenl a more sophisticated treatment than available in the initial calculations. Many of the differences between the ANL and BNL results were then resolved.

3. Since spatial spectral effects are very important in the FMSR, care must be exercised in generating region-wise few-group cross sections. In particular, the local breeding ratio is quite sensitive to the calculation of the local spectrum and treatment of the resolved resonance region. Differences in determining local breeding, especially in the moderator region, can significantly impact the performance of the FMSR.

4. The results of the benchmark calculations indicate that all the methods and data predict essentially the same results, provided the analyses take into account the need to carefully treat the spatial 
dependence of the neutron spectrum. In addition, a consistent fission product treatment is essential.

With regard to the fission product treatment, the following conclusions apply:

1. The initial one-lump model is not adequate for the entire reactor al.though it is' suitable for the fast region.

2. The present groupings of fission products are based on thermal reactor experience and most do not include a scattering matrix. These shortcomings were closely assessed and corrected.

3. Analyses of the benchmark results led to a careful review of the available fission product treatments. A new "two lump".treatment has been developed which predicts results in good agreement with those obitained with an exact treatment. 


\section{REFERENCES}

1. G. J. Fischer and R. J. Cerbone, "The Fast-Mixed Spectrum Reactor Report: Initial Feasibility Study," Brookhaven National Laboratory, BNL-509.76; January 1979.

2. C. R. Weisbin et al., "Fast Reactor Cross Section Processing Codes - Is There a Dollars Worth of Difference Between Them?" Advanced Reactors: Physics, Design and Economics, Edited by Kallfelz and Karain (1974).

3. R. B. Kidman et al., "Difference Between LASL- and ANL-Processed Cross Sections," Los Alamos Scientific Laboratory, LA-7191-MS (1978).

4. W. W. Little el al., "2-DB Users Manual, Revision 1," Battelle Memorial Institute, BNWL-831, Rev. 1 (1969).

5. R. B. Kidman et al.," "LIB-IV, A Library of Group Constants for Nuclear Reactor Calculations," Los Alamos Scientific Laboratory, LA-6260-MS (1970).

6. R. W. Hardie et al.; "I-DX - A One-Dimensional Diffusion Code for Generating Effective Nuclear Cross Sections," Battelle Memorial Institute, BNWL-954 (1969).

7. W. A. Wittkopf, "Lumped Fission Product Neutron Capture Cross Sections for the ENDF/B," BAW-320, December 1966.

8. Y. Kikuch1 et al., "fission Product Fast Reactor Constants Šystem of JNDC," JAERI 1248, November 1978.

9. J. D. Garrison and B. W. Roos; Nucl. Sci.\& Eng., 12 (1962); G^-2112 (1961).

10. W. B. Wilson, T. R. England and R. J. LaBauve, "Multigroup and Few-Group Cross Section for ENDF/BIV Fission Products; the TOAFEW Collapsing Code and Data File of 154-Group Fission Product Cross Sections," LA-7174-MS, March 1978.

11. T. C. Eriglarid, W. B. Wilson and M. G. Stamatelatos, "Fission Product Data for Thermal Reactors," Part II Users Manual for EPRI-CINDER Code and Data, EPRI NR-356, December 1970. 